\title{
Procedural sedation
}

\section{Aspects on methods, safety and effectiveness}

Benjamin Grossmann

optimal

endeavour 2 Genera therapeutic 8

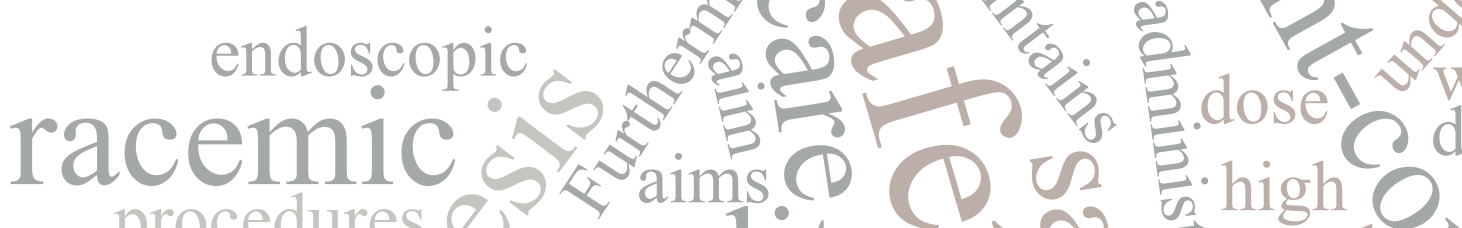
¿ 02 burn $\frac{2}{2}$ procedures \& patients $x$ qual1ty painful 0 clinical $\angle C$ need

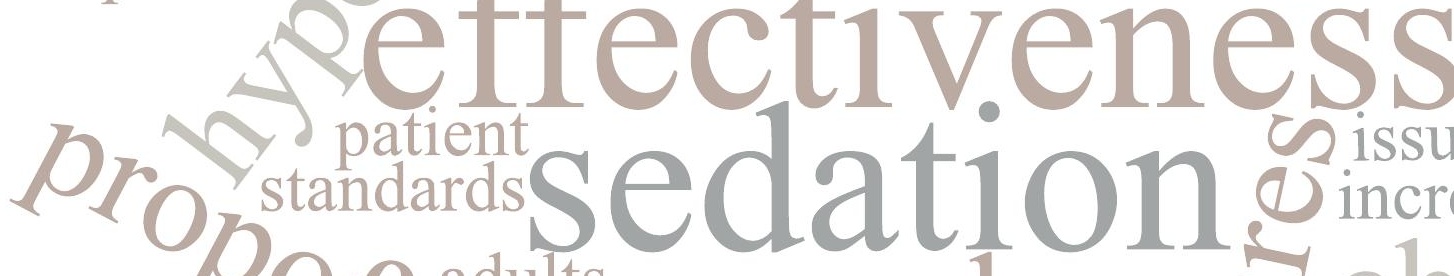

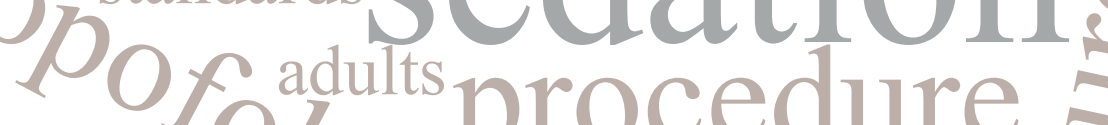
using 07

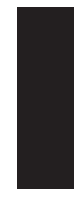

$$
\begin{aligned}
& \text { 10Cecluie } \\
& \text { effective } \mathrm{Cl} \\
& \text { hypothesised o gei } \\
& \text { alternative } \\
& \text { affecting emerge } \\
& \text { wound }
\end{aligned}
$$




\title{
Procedural sedation
}

Aspects on methods, safety and effectiveness

\author{
Benjamin Grossmann
}

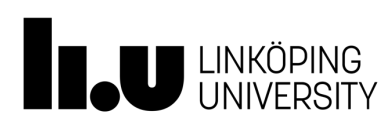

Department of Clinical and Experimental Medicine

Division of Surgery, Orthopaedics and Oncology

Faculty of Medicine and Health Sciences

Linköping University, SE-581 83 Linköping, Sweden 
(c) Benjamin Grossmann, 2019

Cover design: By the author

The published article has been reprinted with the permission of the copyright holder.

Printed in Sweden by LiU-Tryck, Linköping, Sweden, 2019

ISSN 0345-0082

ISBN 978-91-7685-110-4 
Till Karolina och Miriam

"... what counts in life is not the mere fact that we have lived. It is what difference we have made to the lives of others that will determine the significance of the life we lead."

Nelson Rolihlahla Mandela 


\section{Principal supervisor}

Lena Nilsson, MD, PhD, Associate Professor

Department of Medical and Health Sciences

Division of Drug Research

Faculty of Medicine and Health Sciences

Linköping University, Sweden

\section{Assistant supervisors}

Andreas Nilsson, Nurse anaesthetist, PhD

Department of Medical and Health Sciences

Division of Nursing

Faculty of Medicine and Health Sciences

Linköping University, Sweden

Folke Sjöberg, MD, PhD, Professor

Department of Clinical and Experimental Medicine

Division of Surgery, Orthopaedics and Oncology

Faculty of Medicine and Health Sciences

Linköping University, Sweden

\section{Opponent}

Elisabeth Ericsson, Nurse anaesthetist, Associate Professor

Department of Health Sciences

Faculty of Medicine and Health

Örebro University, Sweden 


\section{Committee board}

Mats Enlund, MD, PhD, Associate Professor

Department of Surgical Sciences

Division of Anaesthesiology and Intensive Care

Faculty of Medicine

Uppsala University, Sweden

Lennart Persson, MD, PhD, Associate Professor

Division of Cardiovascular Medicine

Faculty of Medicine and Health Sciences

Linköping University, Sweden

\section{Substitute}

Gunilla Hollman Frisman, Registered nurse, PhD, Associate Professor

Department of Medical and Health Sciences

Division of Nursing

Faculty of Medicine and Health Sciences

Linköping University, Sweden 


\section{TABLE OF CONTENTS}

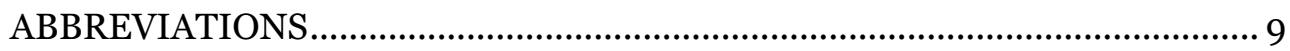

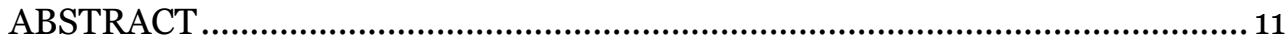

SVENSK SAMMANFATTNING ...................................................................13

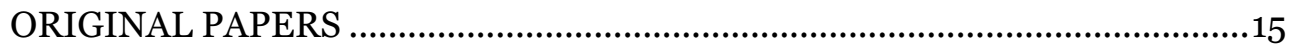

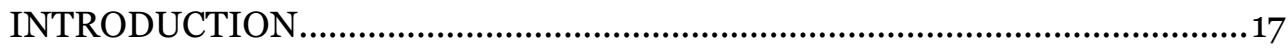

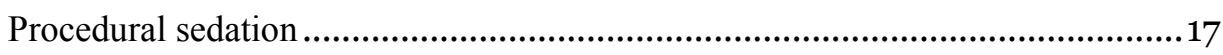

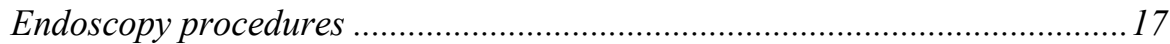

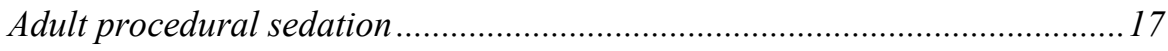

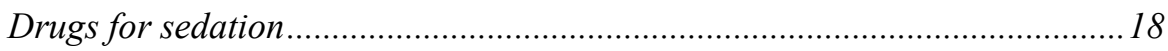

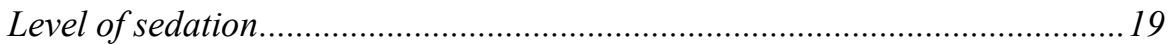

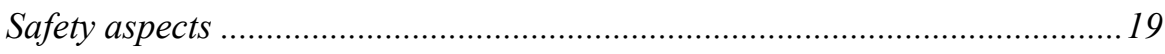

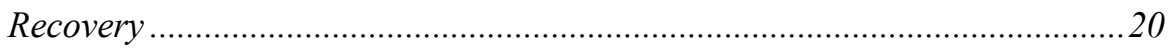

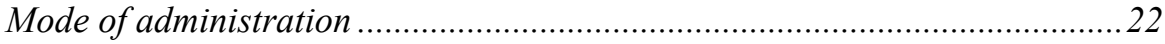

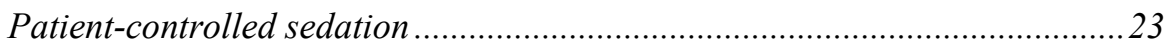

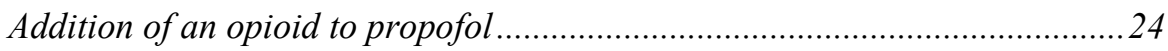

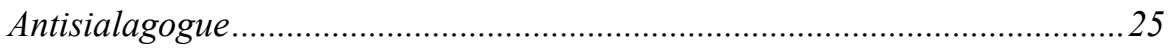

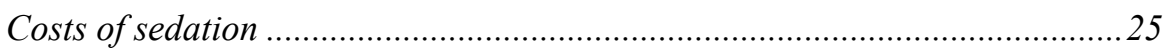

Paediatric Procedural Sedation ............................................................................ 27

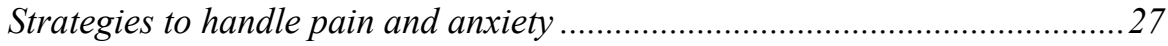

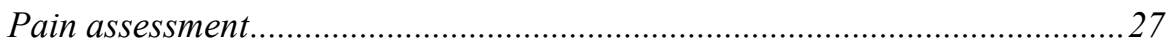

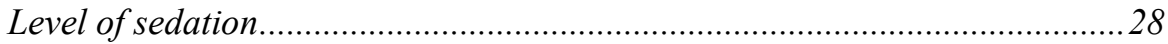

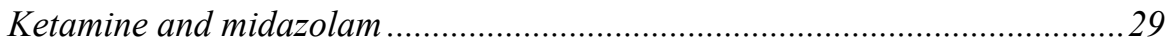

AIMS AND HYPOTHESIS.............................................................................

General aims and hypothesis .........................................................................31

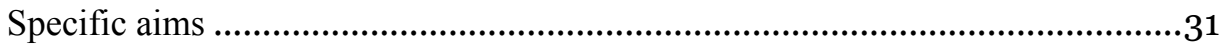

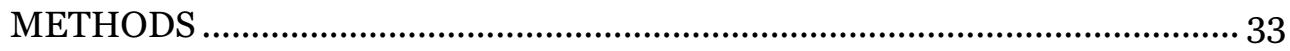

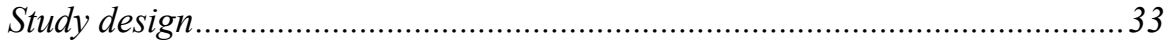

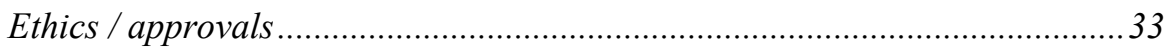

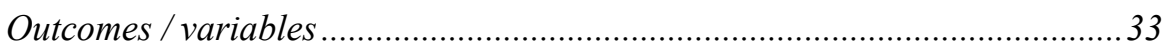




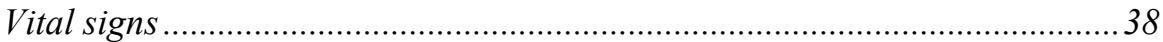

Safety interventions and rescue interventions ................................................... 38

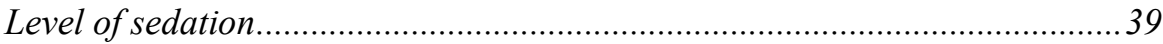

Recovery and patient reported outcome measures …………….......................40

Endoscopists and patient-reported experience measures ................................ 40

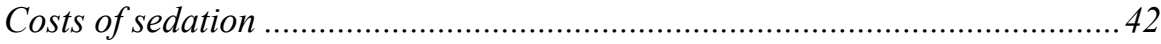

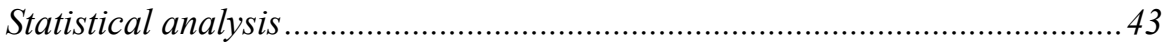

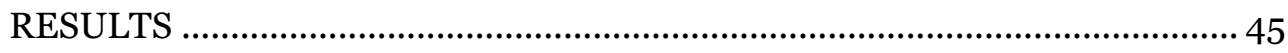

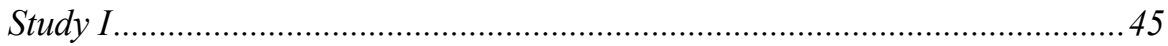

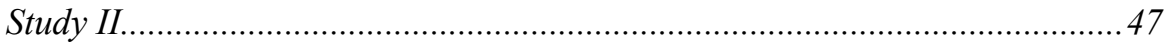

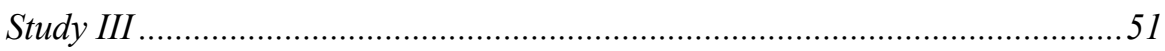

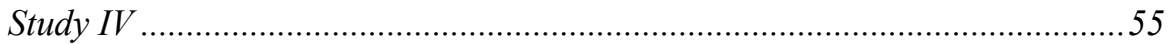

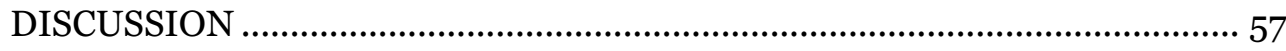

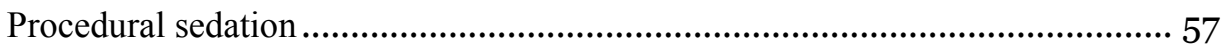

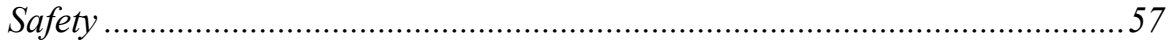

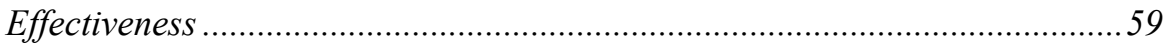

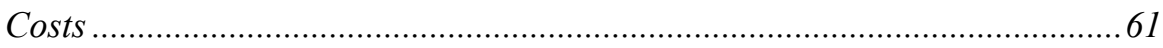

Paediatric procedural sedation ......................................................................... 63

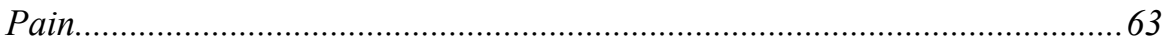

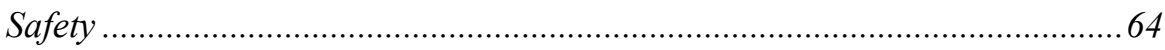

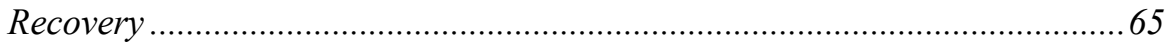

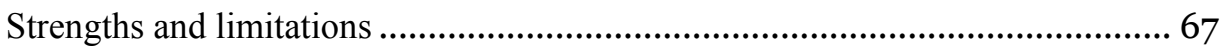

Clinical implications and future research...........................................................69 69

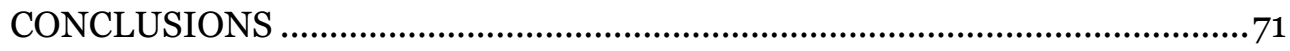

General conclusions .................................................................................... 71

Specific conclusions.......................................................................................71

ACKNOWLEDGEMENTS ………………………................................... 73

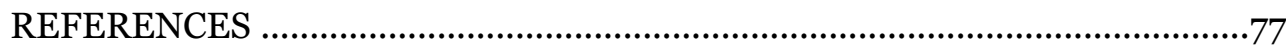





\section{ABBREVIATIONS}

ACS Nurse anaesthetist-controlled sedation

ASA American Society of Anesthesiologists

EBUS Endobronchial ultrasound

ERCP Endoscopic retrograde cholangiopancreaticography

FASS Pharmaceutical Specialties in Sweden

FB Flexible bronchoscopy

FLACC Faces, Legs, Activity, Cry, Consolability scale

GI Gastrointestinal

HR Heart rate

IV Intravenous

IVS Intravenous sedation

MAC Monitored anaesthesia care

NAPS Non-anaesthesiologist-administered propofol sedation

NCS Nurse anaesthetist propofol sedation

NIBP Non-invasive blood pressure

OAA/S Observer's Assessment of Alertness/Sedation Scale

PADSS modified Post Anaesthetic Discharge Scoring System

PCS Patient-controlled sedation

PONV Postoperative nausea and vomiting

PSR Post-Discharge Surgical Recovery scale

QoR-23 Quality of Recovery-23

$\mathrm{SpO}_{2} \quad$ Oxygen saturation

UMSS University of Michigan Sedation Scale

VAS Visual analogue scale 
Procedural sedation - Aspects on methods, safety and effectiveness 


\section{ABSTRACT}

Background: Safety and effectiveness are fundamental principles within the healthcare sector to provide quality of care and health improvement for patients. By ensuring that care is provided based on evidence-based knowledge, risks and complications can be minimised and the use of scarce resources optimised. An increasing demand for diagnostic and therapeutic procedures challenges the traditional methods for sedation regarding safety and effectiveness. It is desirable that the fundamental principles are improved when refining existing or developing new sedation methods. In this doctoral thesis, safety and effectiveness were evaluated for adult patient-controlled sedation (PCS) using propofol during two endoscopic procedures: endoscopic retrograde cholangiopancreaticography (ERCP) and flexible bronchoscopy (FB); and different doses of rectal racemic ketamine for paediatric $(<4$ years $)$ burn wound care.

Methods: Data on vital functions, sedation level, safety interventions, procedure feasibility, patient-reported outcome and experience measures, and recovery, from three clinical randomised controlled trials were collected. Costs of sedation for the endoscopic procedures were compiled in a cost-analysis study.

Results: PCS with propofol and bedside anaesthetic personnel was shown to be a safe and effective alternative method of sedation during ERCP and FB compared with intravenous sedation with midazolam. The PCS method gives stable cardiorespiratory conditions with few adverse events and interventions, with a low risk of oversedation. PCS offers similar (FB) or better (ERCP) procedure feasibility and patient satisfaction during the procedures than midazolam. Recovery after PCS is quick, minimises the risk for prolonged hospitalisation and is thereby a potential cost-saving sedation method. The optimal dose of rectal racemic ketamine, $6 \mathrm{mg} / \mathrm{kg}$ with the addition of $0.5 \mathrm{mg} / \mathrm{kg}$ midazolam during severely painful procedures, gives minimal risk for outbreaks of pain, offers stable vital signs conditions and allows rapid recovery without affecting procedure feasibility.

Conclusions: The sedation method can be adjusted to type of procedure and patient population. PCS with propofol offers an alternative and reliable method for adult sedation during endoscopic procedures, whereas rectal racemic ketamine combined with midazolam provides good conditions for burn care dressing procedures in young children. 
Procedural sedation - Aspects on methods, safety and effectiveness 


\section{SVENSK SAMMANFATTNING}

Bakgrund: Säkerhet och effektivitet är grundläggande principer inom hälso- och sjukvården för att tillhandahålla god vårdkvalitet och förbättrad hälsa för patienter. Genom att utföra arbetet utifrån evidensbaserad kunskap kan risker och komplikationer men även användningen av resurserna optimeras. Den ökade efterfrågan för olika diagnostiska och terapeutiska undersökningar utmanar de traditionella metoderna för sedering gällande säkerhet och effektivitet. Då befintliga eller nya metoder för sedering utvecklas är det önskvärt att de grundläggande principerna förbättras. I denna doktorsavhandling utvärderades säkerhet och effektivitet för patientkontrollerad sedering (PCS) och propofol under två endoskopiska procedurer: endoskopisk retrograd kolangiopankreatografi (ERCP) och flexibel bronkoskopi (FB); samt olika doser för rektalt administrerat racemiskt ketamin för barn ( $<4$ år) vid omläggning av brännskada.

Metoder: Insamling av data gällande vitala funktioner, sederingsnivå, interventioner, genomförbarhet, patientrapporterade utfallsmått och upplevelsemått, och återhämtning genomfördes i tre kliniska randomiserade studier. Kostnader i samband med sedering för ERCP och FB sammanställdes i en kostnadsanalys-studie.

Resultat: PCS med propofol visade sig vara ett säkert och effektivt alternativ för sedering vid ERCP och FB, jämfört med intravenös midazolam administrerad av endoskopipersonal. Metoden gav kardiorespiratorisk stabilitet med få biverkningar och interventioner i båda studierna. Under ERCP resulterade PCS i en markant minskning av risken för översedering jämfört med sedering utförd av anestesipersonal. Hos $20 \%$ av patienterna vid ERCP som gavs midazolam blev undersökningen tvungen att avbrytas på grund av otillräcklig sedering. Dessa kunde framgångsrikt sederas med PCS. Metoden bidrog till snabbare återhämtning men även att reducera oplanerade vårddygn vilket ledde till en potentiell kostnadsbesparing. PCS erbjuder likvärdig (FB) eller förbättrad (ERCP) genomförbarhet med hög patientnöjdhet jämfört med midazolam. Den optimala dosen av rektalt racemiskt ketamin vid procedurer med hög smärtintensitet, såsom omläggning av brännskada, visade sig vara $6 \mathrm{mg} / \mathrm{kg}$, kombinerat med $0.5 \mathrm{mg} / \mathrm{kg}$ midazolam. Dosen ger god smärtlindring utan behov av ytterligare läkemedel, stabila vitala funktioner och snabb återhämtning utan att påverka genomförbarheten. 
Slutsatser: PCS med propofol är en alternativ metod för sedering som är säker och effektiv under ERCP och FB. Vidare kan barn som genomgår smärtsam brännskadeomläggning ges en säker och effektiv vård vid användning av racemiskt ketamin kombinerat med midazolam. 


\section{ORIGINAL PAPERS}

The studies will be referred to by their roman numerals.

I. Nilsson A, Grossmann B, Kullman E, Uustal E, Sjöberg F, Nilsson L. Sedation during endoscopic retrograde cholangiopancreatography: a randomized controlled study of patient-controlled propofol sedation and that given by a nurse anesthetist. Scand J Gastroenterol. 2015;50(10):1285-92.

II. Grossmann B, Nilsson A, Sjöberg F, Nilsson L. Patient-controlled sedation during flexible bronchoscopy: a randomised controlled trial. J Bronchology Interv Pulmonol. [Submitted]

III. Grossmann B, Nilsson A, Sjöberg F, Bernfort L, Nilsson L. Patientcontrolled sedation with propofol for endoscopic procedures - a costanalysis. Acta Anaesthesiologica Scandinavica. [Submitted]

IV. Grossmann B, Nilsson A, Sjöberg F, Nilsson L. Rectal ketamine during paediatric burn wound dressing procedures: a randomised dose-finding study. Burns. [Accepted 12 December 2018] 
Procedural sedation - Aspects on methods, safety and effectiveness 


\section{INTRODUCTION}

\section{Procedural sedation}

A wide range of procedures are performed in healthcare for children and adults with a diagnostic or therapeutic purpose. The procedures can be unpleasant, more or less painful, and some patients — but far from all — experience anxiety and fear. Preventing and treating these conditions is a multidimensional field, which involves pharmacologic, physical and psychologic interventions. This dissertation focuses on the sedation strategy, which is often one of the keys for a successful procedure. Pharmacologic sedation and/or analgesia reduce pain, anxiety and discomfort, but the method needs to be balanced with the demands of patient safety and effectiveness regarding procedure feasibility, patient satisfaction, recovery and costs.

\section{Endoscopy procedures}

Endoscopy is an intervention to examine and treat patients who can be used for several interventions, commonly gastrointestinal (GI) and respiratory procedures.

The GI endoscopy is divided into two areas: the upper GI tract, including the oesophagus, stomach, and upper part of the small intestine, and the lower GI tract, including the rectum and the large intestine. A special form of upper GI endoscopy is endoscopic retrograde cholangiopancreatography (ERCP), which is used to investigate and treat patients with different abnormalities and conditions in the pancreas or gallbladder.

Bronchoscopy is a technique for diagnostic or therapeutic interventions in the respiratory system that uses either a rigid or flexible fibre-optic scope. The latter is an updated version of the rigid bronchoscope and is used more frequently as it causes less discomfort for the patient.

This thesis focuses on ERCP and flexible bronchoscopy (FB).

\section{Adult procedural sedation}

In both GI endoscopy and bronchoscopy, the feasibility of endoscopic procedures depends on the patient to tolerate the endoscope. Even if some endoscopic procedures can be performed without sedation, earlier studies have shown that sedation increases patient satisfaction and the willingness to repeat the procedure (1). According to the American Society for Gastrointestinal Endoscopy and the 
British Thoracic Society guidelines, sedation is recommended during endoscopy $(2,3)$.

\section{Drugs for sedation}

Different sedatives and analgesics can be used and combined to achieve appropriate levels of sedation and analgesia during endoscopic procedures. For a long time, benzodiazepines, mostly midazolam, often with the addition of an opioid, have been used during endoscopy, but during the last two decades propofol has become a widespread competitive alternative due to its fast onset and recovery. Most studies that focused on sedation have been conducted for GI endoscopy, but a few randomised controlled trials (RCT) have been completed for bronchoscopic procedures comparing propofol and midazolam.

The use of propofol compared with intravenous sedation (IVS) that use different sedative agents during GI endoscopy is considered safe, without increased cardiopulmonary complications and giving better sedation regarding procedure feasibility and patient co-operation, and shorter time until recovery and discharge (4). For bronchoscopic procedures propofol has been shown to be safe and reduce recovery time compared to IVS with midazolam (5).

This thesis focuses on the use of midazolam and propofol for sedation during ERCP and bronchoscopy.

Propofol, according to Pharmaceutical Specialties in Sweden (FASS) (6), is a short-acting hypnotic drug with an onset time of between 30 and 40 seconds and with a transient effect due to its rapid metabolism and excretion (4-6 minutes). Upon administration of propofol the initial blood concentration decreases rapidly due to fast distribution to various tissues (alpha phase), and the half-life has been estimated to be 2-4 minutes. In the elimination phase (beta phase), the blood concentration decreases more slowly and the half-life is about 30-60 minutes. The third phase represents the redistribution of propofol from low perfusion tissues. Propofol is primarily metabolised in the liver and excreted in the form of metabolites in the urine.

Midazolam, according to Pharmaceutical Specialties in Sweden (FASS) (7) has primarily a sedative and sleep-inducing effect that sets in about 2 minutes after intravenous (IV) administration, and the maximum effect is achieved after 5-10 minutes. Midazolam is almost completely eliminated by metabolism whereby $30-60 \%$ is estimated to be metabolised in the liver. The half-life elimination of midazolam is between 1.5 and 2.5 hours for healthy volunteers. 


\section{Level of sedation}

Sedation is described as a continuum of states that includes minimal sedation (anxiolysis), moderate ("conscious") sedation, deep sedation, and that, if further deepened, progresses to general anaesthesia (8). The appropriate level of sedation is dependent on both patient and procedural variables that can be difficult to predict. Depth of sedation is influenced by the inter-patient variability of the drug(s) used combined with the variation of discomfort between and during different procedures. Administration and titration of drugs to achieve and maintain a desired level of sedation can be difficult for procedures or interventions with transitory periods and fluctuation in intensity of pain or discomfort.

Most endoscopic procedures are performed during moderate sedation whereby the patient's consciousness is depressed, but the patient still has the ability to respond purposefully to verbal commands, either unstimulated or accompanied by light tactile stimulation. During this level of sedation, the patient has a patent airway and spontaneous ventilation, and cardiovascular stability is usually maintained (8).

There are several validated instruments available for assessing patients' depth of sedation (9). One of the scales commonly used in the clinic and within studies is the Observer's Assessment of Alertness/Sedation Scale (OAA/S) (10) (Table 1).

Table 1.

\begin{tabular}{l|c}
\hline The Observer's Assessment of Alertness/Sedation (OAA/S) Scale \\
\hline Observation & Score level \\
\hline Responds readily to name spoken in normal tone & 5 \\
\hline Lethargic response to name spoken in normal tone & 4 \\
\hline Responds only after name is called loudly and/or repeatedly & 3 \\
\hline Responds only after mild prodding or shaking & 2 \\
\hline Does not respond to mild prodding or shaking & 1 \\
\hline
\end{tabular}

\section{Safety aspects}

Guidelines for sedation during endoscopy are available and aim to minimise risks of adverse events $(2,3,11,12)$. The majority of complications that occur are respiratory depression inducing hypoxia, hypotension and cardiac dysrhythmia (13). Providers administering sedative drugs during GI endoscopy and bronchoscopy need appropriate skills for assessment of different levels of sedation and management of cardiorespiratory complications and rescue drugs to 
be able to intervene if needed $(3,14)$. To minimise risks, pre-procedural assessment is vital to identify potential problems that might occur during the procedure. The American Society of Anesthesiologists (ASA) classification is commonly used to assess risks for cardiorespiratory adverse events (15). Severe respiratory events with aspiration can be minimised by pre-procedural fasting (3, 16). Patients' vital signs should be monitored in connection with the procedure to detect deviations in pulse, blood pressure, saturation, respiration, cardiac electrical activity and level of sedation (2). One way to address safety is by the registration of serious adverse events requiring intervention (17). This can be defined as an event requiring any type of cardiopulmonary intervention or resuscitation, administration of rescue/reversal medication, unplanned procedure termination, emergency surgery and intraprocedural adverse events requiring intervention. Serious adverse events related to sedation are rare: $<1 \%$ for GI endoscopic procedures during sedation performed by anaesthesia professionals (17). Complications during FB have been reported in a range between $<0.1 \%$ to $11 \%$, but no consensus exists regarding the classification of these complications (18).

Conclusions regarding safety for most studies should be drawn with caution due to small and limited study populations. RCTs with thousands of participants are needed to identify serious adverse events and show evidence of potential increased risk for certain methods of sedation or interventions.

\section{Recovery}

Recovery is an important variable to evaluate when answering the question of whether a certain sedation method is effective. Important aspects of recovery are time until fully recovered and quality of recovery. The description of fully recovered differs depending on the scale used. In this thesis we used the Aldrete scale (19) (Table 2) and the modified Post Anaesthetic Discharge Scoring System (PADSS) (20) (Table 3), both used for discharge assessment after anaesthesia or sedation.

The Aldrete score is widely used and well-known, and it evaluates circulation (blood pressure compared with pre-procedural), respiration (ability to take a deep breath), movement (of extremities), consciousness (arousability) and oxygen saturation.

The PADSS consists of assessment of five criteria: vital signs, ambulation, nausea and/or vomiting, pain and surgical bleeding. Both scales assess when the patient is ready to be safely discharged home after sedation or anaesthesia performed on an outpatient basis, but it does not assess "street readiness". 
Table 2.

\begin{tabular}{|c|c|}
\hline \multicolumn{2}{|l|}{ The Aldrete score } \\
\hline Parameters & Score \\
\hline \multicolumn{2}{|l|}{ Activity: able to move voluntarily or on command } \\
\hline Moving all four extremities & 2 \\
\hline Moving two extremities & 1 \\
\hline Not able to move any extremity & 0 \\
\hline \multicolumn{2}{|l|}{ Respiration } \\
\hline Able to breathe deeply and cough freely & 2 \\
\hline Dyspnoea, shallow or limited breathing & 1 \\
\hline Apnoeic & 0 \\
\hline \multicolumn{2}{|l|}{ Circulation } \\
\hline $\mathrm{BP} \pm 20 \mathrm{~mm}$ of $\mathrm{Hg}$ of pre-anaesthetic level & 2 \\
\hline $\mathrm{BP} \pm 20-50 \mathrm{~mm}$ of $\mathrm{Hg}$ of pre-anaesthetic level & 1 \\
\hline $\mathrm{BP} \pm 50 \mathrm{~mm}$ of $\mathrm{Hg}$ of pre-anaesthetic level & 0 \\
\hline \multicolumn{2}{|l|}{ Level of consciousness } \\
\hline Fully awake & 2 \\
\hline Arousable on calling & 1 \\
\hline Not responding & 0 \\
\hline \multicolumn{2}{|l|}{$\mathrm{O}_{2}$ saturation } \\
\hline Able to maintain $\mathrm{O}_{2}$ saturation $>92 \%$ on room air & 2 \\
\hline Needs $\mathrm{O}_{2}$ inhalation to maintain $\mathrm{O}_{2}$ saturation $>90 \%$ & 1 \\
\hline $\mathrm{O}_{2}$ saturation $<90 \%$ even with $\mathrm{O}_{2}$ supplementation & 0 \\
\hline
\end{tabular}

Abbreviations: $\mathrm{BP}=$ blood pressure 
Table 3.

\begin{tabular}{|c|c|c|}
\hline \multicolumn{3}{|c|}{ The modified Post Anaesthetic Discharge Scoring System (PADSS) } \\
\hline Category & Description & Score \\
\hline Vital signs & $\begin{array}{l}<20 \% \text { of preoperative value } \\
20-40 \% \text { of preoperative value } \\
>40 \% \text { of preoperative value }\end{array}$ & $\begin{array}{l}2 \\
1 \\
0\end{array}$ \\
\hline Ambulation & $\begin{array}{l}\text { Steady gait; no dizziness } \\
\text { With assistance } \\
\text { No ambulation; dizziness }\end{array}$ & $\begin{array}{l}2 \\
1 \\
0\end{array}$ \\
\hline Nausea or vomiting & $\begin{array}{l}\text { Minimal } \\
\text { Moderate } \\
\text { Severe }\end{array}$ & $\begin{array}{l}2 \\
1 \\
0\end{array}$ \\
\hline Pain & $\begin{array}{l}\text { Minimal } \\
\text { Moderate } \\
\text { Severe }\end{array}$ & $\begin{array}{l}2 \\
1 \\
0\end{array}$ \\
\hline Surgical bleeding & $\begin{array}{l}\text { Minimal } \\
\text { Moderate } \\
\text { Severe }\end{array}$ & $\begin{array}{l}2 \\
1 \\
0\end{array}$ \\
\hline
\end{tabular}

There are important aspects of recovery to evaluate after the patients have left the hospital, i.e. alertness, pain and activity. In this thesis we used two scales, The Post-discharge Surgical Recovery Scale (PSR) (21) and the Quality of Recovery (QoR-23) (22), which both assess quality of recovery. The PSR is a 12-item questionnaire assessing health status and activity post-discharge whereby a higher score indicates positive recovery. The QoR-23 is a 23 -item questionnaire to assess recovery regarding the patients' emotional state, physical comfort and physical independence.

The results from recovery assessment before and after discharge are important variables when assessing the results, not only regarding the effectiveness from a hospital point of view for a certain method of sedation, but also in terms of patient-reported measures.

\section{Mode of administration}

Sedation performed by monitored anaesthesia care (MAC) has traditionally been the standard and is considered safe due to highly qualified personnel, not exclusively anaesthesia personnel, performing moderate to deep sedation. An advantage of MAC is that sedation can be provided for patients with difficult cardiorespiratory conditions (23). Rex et al. (2009) conducted a retrospective study based on over 640,000 patients and concluded that non-anaesthesiologistadministered propofol sedation (NAPS) is safe and feasible when applied on 
patients with ASA grade I to II, but for patients with severe illnesses (ASA $\geq 3$ ) the presence of anaesthetists can possibly increase patient safety (24). NAPS, in contrast to MAC, uses less propofol without compromising safety or procedural quality (23). NAPS is carried out by non-anaesthesiologists in several European countries within the field of endoscopy based on recommendations and training issued by the European Society of Gastrointestinal Endoscopy and the European Society of Gastroenterology and Endoscopy Nurses and Associates (11). Procedural sedation using propofol administered by trained registered nurses or endoscopic teams has been shown to be performed with maintained patient safety during endoscopy (25). Due to few studies and only one meta-analysis (5) within the field, similar conclusions are difficult to draw for bronchoscopy. Bronchoscopic studies comparing NAPS with midazolam have shown similar safety and feasibility $(26,27)$. Administration of propofol by the patient using a patient-controlled sedation (PCS) device has been shown to be an alternative method of sedation which reduces the risk for rescue interventions for sedationrelated adverse events compared with NAPS (28). Without reaching significant differences in the meta-analysis, the number of incidences of oxygen desaturation, hypotension and bradycardia was lower for PCS compared with NAPS (28). Both the propofol doses used and the incidence of oversedation were lower with PCS but not significant compared with NAPS. The operator and patient satisfaction were similarly high for both methods (28).

\section{Patient-controlled sedation}

Patient-controlled sedation (PCS) was originally introduced in 1988 by using a device aimed at patient-controlled analgesia, but using midazolam to decrease anxiety for two patients in an intensive care unit (29). Since then, PCS has been studied in various settings, and comparisons have been made with different modes of administration, drugs and doses.

The idea of PCS is to allow the patient to administer intermittent doses of drugs according to their perception of pain and anxiety or feedback from physiologic variables. Depending on the planned procedure or intervention the device can be prepared with different drugs and with different limitations on the number or size of doses. During the procedure patients may request delivery of drug(s) to handle discomfort or pain. An increased concentration of the drug(s) affects patients' consciousness until a point where further requests are not possible. When the concentration is decreased or the stimuli increase, the patients are able to request additional doses again.

Doses administered with PCS vary in bolus size, infusion rate and lockout interval period, as well as if fixed additional doses are given before or during a procedure or if a continuous background infusion is used. Some endoscopic 
procedures have combined PCS with a background infusion with a targetcontrolled infusion (TCI) system (30).

\section{The sense of control}

The primary difference between the traditional administration of drugs by health care personnel and patient-controlled systems is the sense of control for the patient. Pain relief and satisfaction in connection with patient-controlled systems vary between individuals depending on an individual's "locus of control" (31). Either they believe one can control one's own life (internal locus of control) or they believe that life is controlled by outside factors like chance or fate, which the person cannot influence (external locus of control) (32). Patients with an internal locus of control experience lower levels of pain and higher satisfaction in contrast to patients with an external locus of control (31). The sense of being in control has been shown to increase satisfaction for patients using PCS, who stated that they appreciated the possibility to choose their level of sedation during the procedure (33). For some patients, PCS does not seem to be the optimal method of sedation. Lee et al. tried to give explanations for why some patients are unwilling to use PCS again if needed. In a descriptive study they showed that female sex, age $\leq 50$ years, high doses of propofol, low satisfaction scores and late side-effect(s) were independent factors that affected the unwillingness to use PCS in possible future procedures (34). Another prospective randomized study found that apart from the fact that younger age and high anxiety levels negatively affected preferences for PCS, the majority of unwilling patients were afraid to be responsible for their sedation (35).

\section{Addition of an opioid to propofol}

There are strong synergistic effects in the combination of propofol and opioids (36). The addition of an opioid, mostly alfentanil but also remifentanil, during sedation with propofol using PCS has been evaluated in several studies. Alfentanil and remifentanil have been considered safe and feasible when combined with propofol in PCS during endoscopy $(37,38)$. The addition of alfentanil increases procedure feasibility but affects respiratory stability (39). A disadvantage of using remifentanil is the increased risk for respiratory depression and nausea compared with alfentanil (40). Due to the increased risk for unintended deep sedation when using remifentanil during procedural sedation, patients and procedures need to be carefully selected, and providers must have appropriate knowledge, experience and equipment to handle acute and critical events during the procedure (41). Alfentanil has been used clinically by nonanaesthesia personnel and has the disadvantage of prolonging recovery compared 
with remifentanil (37), and it increases respiratory complications compared with propofol alone (39).

Propofol without the addition of opioids, administered by PCS or a nurse anaesthetist, could be an alternative method of sedation with the possibility to increase procedure effectiveness in connection with ERCP.

\section{Antisialagogue}

Co-administration of an antisialagogue before bronchoscopy with the goal to reduce airway secretion is common. Glycopyrronium is an anticholinergic agent, which blocks the activity of muscarinic receptors and thereby reduces secretions in the mouth, throat, airway and stomach (reduces acidity) and blocks cardiac vagal inhibitory reflexes.

Morphine-scopolamine is a combination of an opioid and a sedative drug with secretion-inhibiting effects, and the combination has a pronounced central depressive effect (42). Compared with glycopyrronium, scopolamine has been shown to be more effective in reducing secretion, but it has a sedative effect (43). Other studies report that the use of anticholinergics does not result in clinically meaningful reduction of secretion, but instead has a cardiovascular effect and increases patients' heart rate and blood pressure $(44,45)$.

To the best of our knowledge, only one study has evaluated PCS for bronchoscopy (46); however, in that study PCS was combined with a background infusion with propofol combined with ketamine or alfentanil. As noted earlier, opioids increase the risk for respiratory adverse events and prolonged recovery. The use of PCS with only propofol together with a non-opioid antisialagogue could optimise recovery and be a feasible sedation alternative for bronchoscopy.

\section{Costs of sedation}

Health economics evaluation aims to assess the costs and health effects associated with the use of resources in health care. To study the health economics and costs involved for different methods of sedation during endoscopy could be of importance for the decision-making processes within health care when considering alternatives.

Not only the number of endoscopic procedures but also the use of propofol for sedation during endoscopy has increased during the last decade (47). Propofol has pharmacological advantages, but local or national regulations in many countries require anaesthesia personnel to monitor the sedation to ensure patient safety. Concerns have been raised that the increased direct costs for drugs and the presence of anaesthesia personnel are not justified by the clinical benefits. Costs for drugs are minor in comparison with the costs for anaesthesia personnel, and 
who administers sedation could therefore be a key issue when reducing costs of sedation (48). Those cost-analyses available $(35,49)$ have included few and only direct costs such as materials, drugs and personnel during the procedure. Vargo (50) expressed that cost-analysis needs to include additional cost items to be able to answer questions regarding costs for different methods of sedation. Additional direct costs i.e. cost for affected recovery but also indirect costs such as loss of production or unpaid work should be addressed (50). 


\section{Paediatric Procedural Sedation}

Procedural sedation methods for children and adults differ, and a certain way of sedation that is successful for adults can be difficult to apply in children. Within the paediatric group important variables (pharmacokinetics and pharmacodynamics) are diverse, besides the differences in each individual's physical and emotional growth and development. An infant of $5 \mathrm{~kg}$ probably needs a different sedation strategy compared with a $70 \mathrm{~kg}$ teenager, and a child of 3 years who seems to be fearless might have a different reaction to an intravenous (Study IV) cannula than a 12-year-old introverted child.

\section{Strategies to handle pain and anxiety}

The success of paediatric procedures is dependent on a co-operative, relaxed and pain-free child. Therefore, sedation is a useful method to reduce pain, anxiety and optimise procedural conditions.

Depending on the type of procedure the severity of pain varies. Pain in connection with removal of IV lines or catheters is perceived to be mild but not painless, dressing change or removal increases pain up to moderate, and cleaning or care of excoriated skin is considered to cause moderate to severe pain (51). If management to control pain repeatedly fails, anxiety increases, pain sensitivity is altered, and behavioural changes appear on the neuropsychiatric and social level (52), but the child is also affected psychologically, which may influence their present and future interactions with health care (53). Increased stress caused by pain or anxiety during painful procedures also decreases wound healing and increases risk of infections (54). There are different strategies to apply when children need to undergo procedures involving pain or discomfort. Depending on factors and settings, non-pharmacological strategies such as heat and cold therapy or behavioural distraction, e.g. a computer tablet, can be applied, but mostly pharmacological sedation using different drugs and routes of administration is used (51).

\section{Pain assessment}

There are different pain rating scales for children available depending on age (55). Assessment of the acute pain of newborns can be done with the Premature Infant Pain Profile whereas the Faces scale is validated and used to assess the pain intensity for children $\geq 3$ years, and numerical/visual analogue scales can be used for children $\geq 5$ years. The Faces, Legs, Activity, Cry, Consolability (FLACC) Scale (56) (Table 4) is based on behavioural indicators to assess pain for children aged 2 months to 7 years. It consists of five categories, and each 
category has a score between 0 and 2, resulting in a total score of 0 to 10 ; the higher the score, the greater the pain.

Table 4.

\begin{tabular}{|c|c|c|c|}
\hline \multicolumn{4}{|c|}{ The FLACC scale } \\
\hline & \multicolumn{3}{|c|}{ Scoring } \\
\hline Categories & $\mathbf{0}$ & 1 & 2 \\
\hline Face & $\begin{array}{c}\text { No particular } \\
\text { expression or smile }\end{array}$ & $\begin{array}{l}\text { Occasional grimace or } \\
\text { frown, withdrawn, } \\
\text { disinterested }\end{array}$ & $\begin{array}{l}\text { Frequent to constant } \\
\text { quivering chin, } \\
\text { clenched jaw }\end{array}$ \\
\hline Legs & $\begin{array}{l}\text { Normal position or } \\
\text { relaxed }\end{array}$ & Uneasy, restless, tense & $\begin{array}{l}\text { Kicking or legs } \\
\text { drawn up }\end{array}$ \\
\hline Activity & $\begin{array}{l}\text { Lying quietly, normal } \\
\text { position, moves easily }\end{array}$ & $\begin{array}{l}\text { Squirming, shifting } \\
\text { back/forth, tense }\end{array}$ & $\begin{array}{l}\text { Arched, rigid, or } \\
\text { jerking }\end{array}$ \\
\hline Cry & $\begin{array}{l}\text { No cry (awake or } \\
\text { asleep) }\end{array}$ & $\begin{array}{l}\text { Moans or whimpers, } \\
\text { occasional complaint }\end{array}$ & $\begin{array}{l}\text { Crying steadily, } \\
\text { screams or sobs, } \\
\text { frequent complaints }\end{array}$ \\
\hline Consolability & Content, relaxed & $\begin{array}{c}\text { Reassured by } \\
\text { occasional touching, } \\
\text { hugging, or being talked } \\
\text { to, distractible }\end{array}$ & $\begin{array}{l}\text { Difficult to console } \\
\text { or comfort }\end{array}$ \\
\hline
\end{tabular}

\section{Level of sedation}

A number of sedation scales are available for assessing levels of sedation in children (9). Not all are validated and tested for reliability, and these scales may be very detailed with numerous items which make them difficult to use in a clinical setting (e.g. The Comfort Scale with 40 items). Two scales that are good quality and easy to use are the Dartmouth Operative Conditions Scale (DOCS) and the University of Michigan Sedation Scale (UMSS). DOCS compared to UMSS assess not only consciousness and pain but also vital signs, movements and side effects. The advantage for UMSS is that it contains few items thus enabling fast assessment of sedation in clinical settings. The scale is valid and reliable for children between 6 months and 12 years (57) and an increased score indicates deeper sedation (Table 5).

Table 5.

University of Michigan Sedation Scale (UMSS)

\begin{tabular}{l|l}
\hline 0 & Awake and alert \\
\hline 1 & Minimally sedated: tired/sleepy, appropriate response to verbal conversation and/or sound \\
\hline 2 & $\begin{array}{l}\text { Moderately sedated: somnolent/sleeping, easily aroused with light } \\
\text { tactile stimulation or a simple verbal command }\end{array}$ \\
\hline 3 & Deeply sedated: deep sleep, arousable only with significant physical stimulation \\
\hline 4 & Unarousable \\
\hline
\end{tabular}




\section{Ketamine and midazolam}

Racemic ketamine has been used for decades within the context of burn care. It was first studied on burned children in the late 60s (58) and considered to be safe and feasible during surgery. Emergent reactions (agitation, delirium, unpleasant hallucinations) are a known side effect of racemic ketamine. The concomitant use of midazolam has traditionally been a way to minimise these reactions, but has in recent years been disputed (59).

The combination of racemic ketamine and midazolam, compared with each drug alone, is more effective regarding sedation levels and tolerance for painful intervention without increasing complications (60), and tolerance increases with higher doses of racemic ketamine combined with midazolam (61). Depending on the type of procedure and perceived pain, the dosage for rectal racemic ketamine varies widely (62-64).

\section{Routes of administration}

Administration of drugs in children can be challenging. The decision about the administration route is mostly based on the child's age and previous experience. Choosing the "wrong" route may result in difficulties in administering the drug and uncertainty about which dose has reached the child as well as the issue of lost confidence and trust between the caregiver and the child, which may affect the relationship with health care.

Oral, IV, rectal and intranasal routes are possible racemic ketamine administration routes. The effectiveness of sedation is similar between oral and rectal administration but has been shown to shorten recovery time compared to the IV route (65). Racemic ketamine administered intravenously or rectally has similar half-life elimination, but rectal administration has a lower bioavailability (51\%) (66). The advantage of rectal administration is the partial bypass of the first metabolism compared with the oral and nasal administration (67). The rectal uptake of a liquid solution can be interrupted due to absorption by defaecation or incorrect rectal application. The rectal route is feasible for infants and most toddlers, but with increasing age there may be a lack of patient acceptability (68). An expert review within the field of analgesia and sedation for children undergoing burn wound care has given recommendations for rectally administered midazolam, but none for rectal racemic ketamine (69). A dosefinding study for racemic ketamine combined with a fixed dose of midazolam could therefore be of great value in finding an optimal dose. 
Procedural sedation - Aspects on methods, safety and effectiveness 


\section{AIMS AND HYPOTHESIS}

\section{General aims and hypothesis}

This thesis emerged from clinical issues and the endeavour to provide safe and effective care for patients undergoing diagnostic and therapeutic procedures.

The general aim was to evaluate safety and effectiveness during endoscopic procedures for adults using patient-controlled sedation with propofol and safety and effectiveness for children having rectal racemic ketamine during severely painful procedures.

The general hypothesis was that patient-controlled sedation with propofol is a safe and effective alternative method for sedation, which maintains the need for high quality standards for the procedure and the patient. Furthermore, we hypothesised that an optimal dose of rectal-administered racemic ketamine for children during burn wound care would increase effectiveness without affecting safety or procedure quality.

\section{Specific aims}

\section{Study I}

- To compare patient safety, procedure feasibility, recovery and patients' experiences using patient-controlled sedation with propofol, nurse anaesthetistcontrolled sedation with propofol, and standard care-midazolam administered by the procedure team (control group) in connection with the endoscopic retrograde cholangiopancreatography procedure.

\section{Study II}

- To compare the proportion of patients ready for discharge (with a modified Post Anaesthetic Discharge Scoring System score of 10) at 2 hours after flexible bronchoscopy using patient-controlled sedation with propofol or standard caremidazolam administered by the procedure team (control group).

- To compare patient safety, procedure feasibility, recovery, patients' satisfaction and quality of post-discharge recovery between the groups mentioned above.

- To compare two different premedications: subcutaneous morphinescopolamine and intramuscular glycopyrronium regarding patient safety, procedure feasibility, recovery and patients' satisfaction in connection with flexible bronchoscopy. 


\section{Study III}

- To compare the direct costs of patient-controlled sedation with propofol, nurse anaesthetist propofol sedation and standard care-midazolam administered by the procedure team (control group) for endoscopic retrograde cholangiopancreatography and flexible bronchoscopy procedures.

\section{Study IV}

- To compare three different doses of rectally-administered racemic ketamine during paediatric wound burn care procedure regarding:

o pain

- procedure feasibility and recovery

$\circ$ patient safety-level of sedation, vital signs, side effects and adverse events 


\section{METHODS}

The studies covered different procedures, different age groups and men and women. Intravenous midazolam sedation provided by the endoscopic team was used as the control method in Studies I, II and III. In the methods and results section, we have chosen the expression "Control" for these respective groups. In Study I this group was named "Midazolam", and in Study II and III "Control". PCS with propofol with a bedside nurse anaesthetist was used as the intervention method in Studies I, II and III. In the methods and results section, we have chosen the expression "PCS" for these respective groups. In Study I this group was named "PCS" and in Study II and III "PCS-MS" (premedication with morphine-scopolamine) or "PCS-G" (premedication with glycopyrronium).

\section{Study design}

The design for three of the clinical studies (Studies I, II and IV) was prospective, randomised and controlled, and one study was a retrospective cost analysis (Study III) based on data from Study I and II. Blinding was used in two studies: Study II was single-blinded for the bronchoscopist regarding administered premedication in the PCS groups, and Study IV was double-blinded for patients and personnel attending during and after the procedure regarding the dose of racemic ketamine. The design in Study I was partial cross-over, as patients receiving insufficient sedation with midazolam repeated the procedure with PCS. Parallel groups were used for Study II and IV. Participants were adults, except for Study IV which had a paediatric study population. Studies included were performed in a single centre, Linköping University Hospital, Sweden. An overview of all the study characteristics and methods is presented in Table 6.

\section{Ethics / approvals}

All studies had ethical approval from the Regional Ethics Review Board in Linköping, and the Swedish Medical Products Agency approved the clinical drug trial for Study II and IV. The studies were registered in public registers: clinicaltrials.gov (Study I) and the European Clinical Trials Database (Studies II and IV).

\section{Outcomes / variables}

Patient safety and effectiveness were analysed using surrogate variables (Table 6); patient safety was assessed by using vital signs data from the surveillance 
monitor, adverse events and interventions to stabilise cardiorespiratory functions and depth of sedation; effectiveness was evaluated using procedure feasibility, interrupted/aborted procedures and recovery; and quality of sedation was evaluated by pain, patient satisfaction and occurrence of side effects. Costs were analysed by calculating direct costs for sedation (Table 6). 


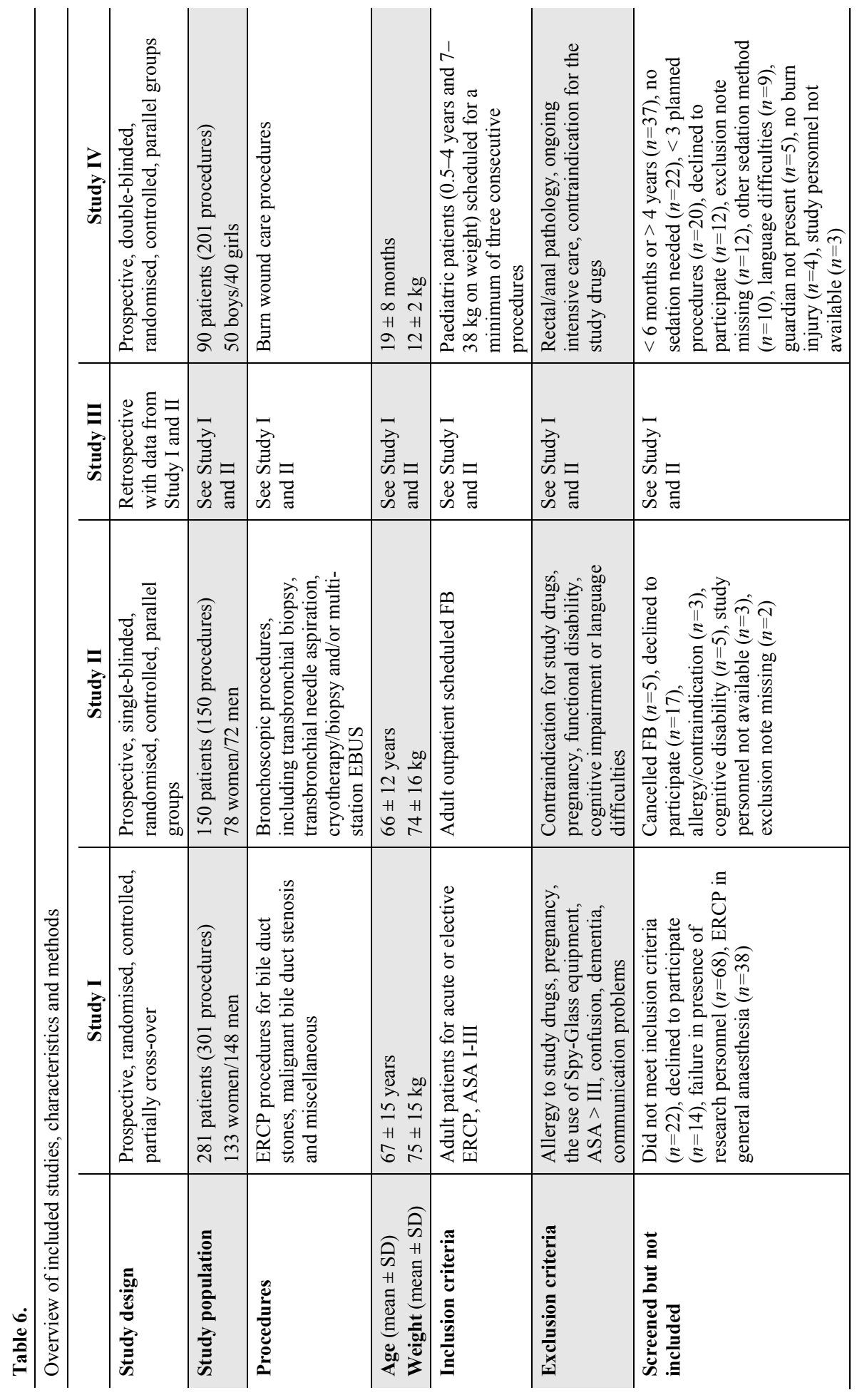




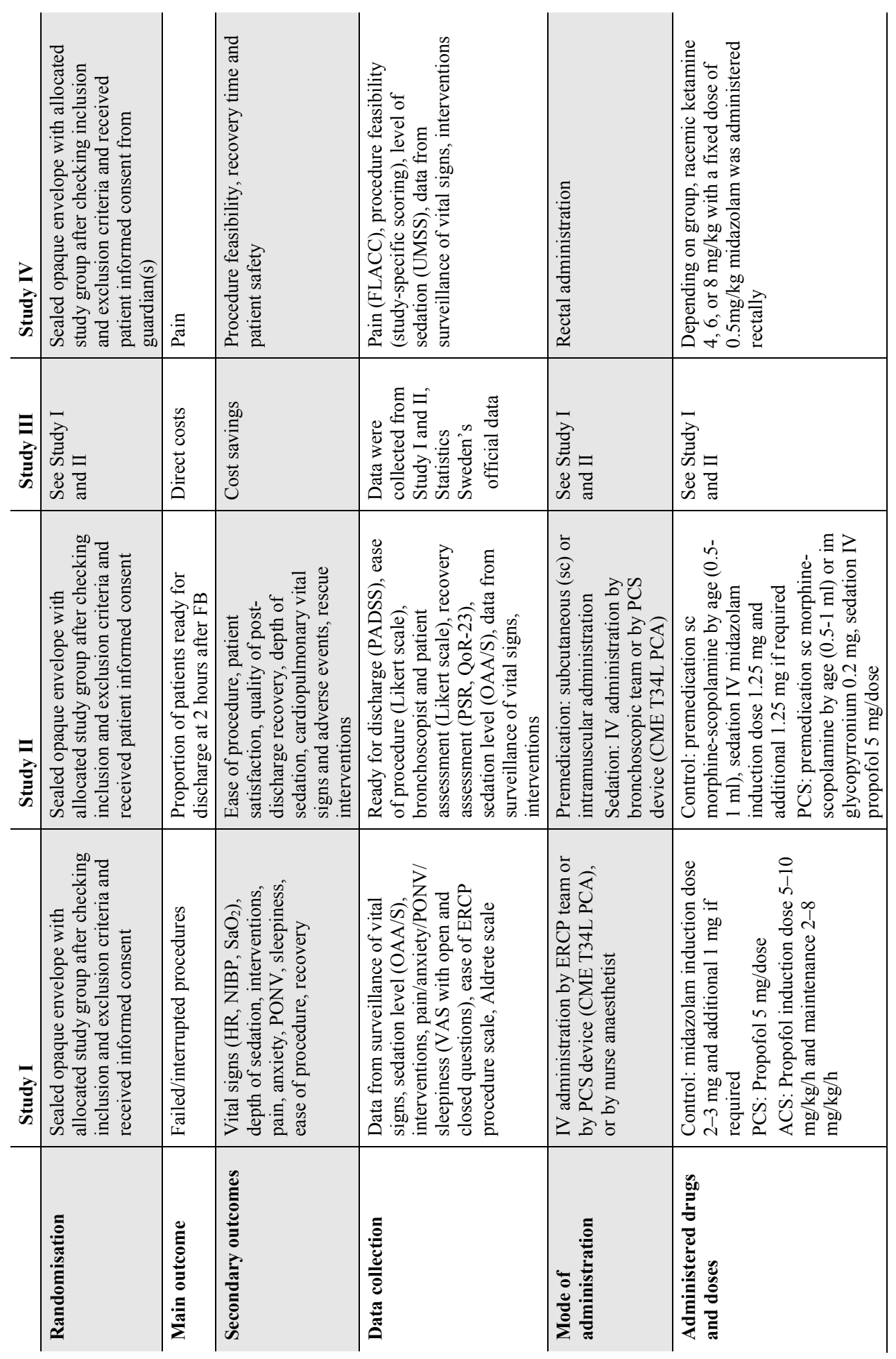




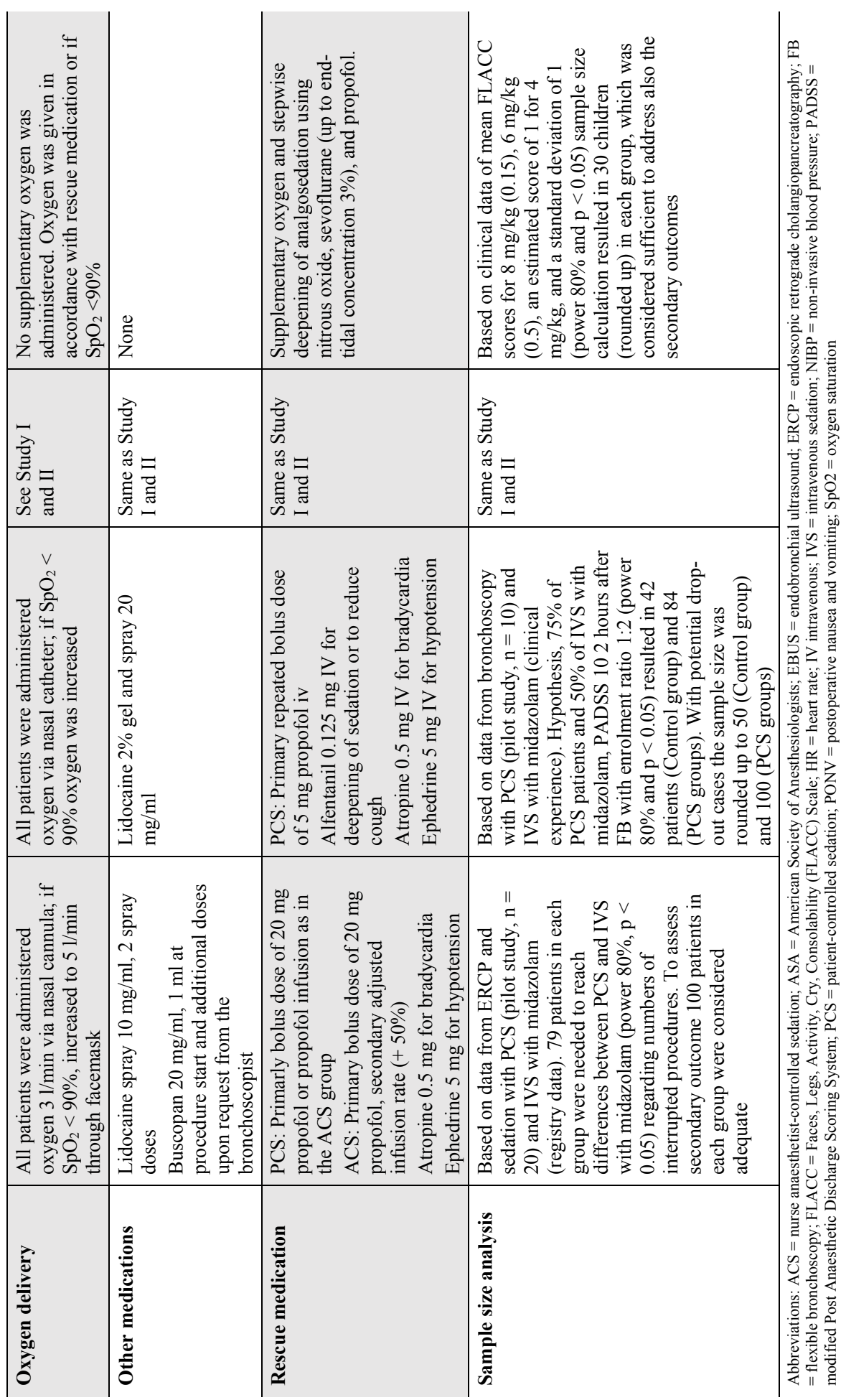




\section{Vital signs}

Cardiorespiratory data for clinical studies were based on periprocedural monitoring of vital signs using the IntelliVue MP30 (Philips Healthcare, Best, the Netherlands) (Studies I and II) and the Masimo SET ${ }^{\circledR}$ pulse oximeter (Masimo Corporation, Irvine, USA) (Study IV). Vital signs were collected every 5 minutes periprocedurally (Studies I, II and IV) and every 5 (Study IV), 10 (Study I) or 15 (Study II) minutes post-procedurally.

\section{Safety interventions and rescue interventions}

In the event of affected vital signs (Table 7) appropriate interventions from the endoscopic personnel or nurse anaesthetist were undertaken to stabilise cardiorespiratory functions. These were: upon the start of hypoxemia oxygen flow was increased (Studies I and II) or supplementary oxygen was administered (Study IV); during hypotension (for two consecutive measurements) IV ephedrine was administered (Studies I and II); episodes of bradycardia were treated with IV atrophine (Studies I and II); patients with respiratory depression were encouraged to take deep breaths (Studies I and II); semi-obstructed or obstructed airways were solved with appropriate airway manoeuvres with the possibility to ventilate by mask or if needed to intubate the patient; events of apnoea $>30$ s and $\mathrm{SpO}_{2}<90 \%$ with assisted ventilation (Study II). A responsible anaesthesiologist was always available nearby via pager. If patient discomfort or procedure feasibility were affected due to insufficient sedation in Study I or II: 1) patients were encouraged to push the administration button for the PCS; 2) additional sedation was administered by the nurse anaesthetist as bolus dose(s) (Studies I and II) or by infusion with infusion pump (Study I). In Studies I and II the control groups were administered repeated IV midazolam according to clinical routine: $1 \mathrm{mg}$ upon request (Study I); $1.25 \mathrm{mg}$ upon request (Study II). Alfentanil $0.125 \mathrm{mg}$ was used as rescue medication in Study II for all groups and could be administered upon request from the bronchoscopist to reduce cough or deepen sedation. In Study IV stepwise rescue medication was administered together with supplementary oxygen: 1) nitrous oxide; 2) sevoflurane; 3) IV propofol. 
Table 7.

\begin{tabular}{l|c|c}
\hline \multicolumn{2}{l}{ Definition of affected vital signs } & Adults (Studies I and II) \\
\hline Hypoxaemia $\left(\mathrm{SpO}_{2}, \%\right)$ & $<90$ & Children (Study IV) \\
\hline Hypotension (NIBP, $\mathrm{mmHg})$ & $<80$ (Study I) & $<90$ \\
\hline Bradycardia (BPM) & $<90$ (Study II) & - \\
\hline Tachycardia (BPM) & - & $<80$ (6-12 months) \\
\hline $\begin{array}{l}\text { Respiratory depression } \\
\text { (breaths/min) }\end{array}$ & $<8$ & $>20 \%$ increase from baseline \\
\hline
\end{tabular}

Limits for children according to references for bradycardia (70), tachycardia (71) and respiratory depression (70)

Abbreviations: $\mathrm{BPM}=$ beats per minute; $\mathrm{NIBP}=$ non-invasive blood pressure; $\mathrm{SpO}_{2}=$ blood oxygen saturation

Patients randomised to the PCS groups in Study I and II administered propofol $10 \mathrm{mg} / \mathrm{ml}$ via a PCS device (T34L PCA, Caesarea Medical Electronics Ltd., Lichtenstein, Germany) without lockout periods. By pressing the delivery button, patients self-administer a bolus of $5 \mathrm{mg}$ of propofol $(0.5 \mathrm{ml})$. The delivery time was approximately 8 seconds, with the possibility to administer a maximum of $35 \mathrm{mg}$ propofol $/$ minute.

Propofol $10 \mathrm{mg} / \mathrm{ml}$ was also administered as rescue medication for insufficient sedation in the PCS groups (Studies I and II) but also for patients randomised to the ACS group (Study I) as an infusion with an infusion pump (induction dose $0.5 \mathrm{mg}-1.0 \mathrm{ml} / \mathrm{kg}$, maintenance dose $2-8 \mathrm{mg} / \mathrm{kg} /$ hour) (Study I) or with the PCS device (Study II) controlled by a nurse anaesthetist.

Premedication was randomised and blinded for the bronchoscopist in Study II and consisted of subcutaneous morphine-scopolamine with a dosage according to age (18-54 years, $1.0 \mathrm{ml}$; 55-65 years, $0.75 \mathrm{ml}$; $>65$ years, $0.5 \mathrm{ml})$ or intramuscular glycopyrronium $0.2 \mathrm{mg}$.

Children in Study IV were administered a mixture of the randomised dose ( $4 \mathrm{mg}$, $6 \mathrm{mg}$ or $8 \mathrm{mg}$ ) of rectal racemic ketamine combined with a fixed dose of $0.5 \mathrm{mg}$ midazolam. To maintain blinding, a designated nurse not involved in sedation or wound care mixed the drugs with sodium chloride to obtain a total volume of $5 \mathrm{ml}(<20 \mathrm{~kg})$ or $10 \mathrm{ml}(\geq 20 \mathrm{~kg})$.

\section{Level of sedation}

Assessment of depth of sedation during procedures was carried out using validated sedation scales, the Observer's Assessment of Alertness/Sedation (OAA/S) Scale (10) for adults (Studies I and II) and the University of Michigan Sedation Scale (UMSS) (57) for children (Study IV). During the procedure 
patients were regularly assessed every fifth minute by verbal and/or physical stimulation depending on the level of sedation.

For patients administered propofol (Studies I and II) the goal was to be comfortable and sleepy, equivalent to OAA/S $\geq 3$ (Study I), and in Study II the target sedation level was slightly lower (OAA/S 2) due to the sensitiveness of the airway. The control groups' sedation was carried out according to standard care to achieve similar comfort and sedation for the patient as for the patients with propofol.

\section{Recovery and patient reported outcome measures}

Upon procedure completion patients were evaluated according to validated recovery scales, the Aldrete score (72) (Study I) and the modified Post Anaesthetic Discharge Scoring System (PADSS) (20) (Study II). Evaluation of the degree of recovery was assessed every 15 minute post-procedure. ERCP patients with an Aldrete score $\geq 7$ after completion of the procedure were forwarded to the surgical ward for full recovery (score $\geq 9$ ). Patients after completion of the bronchoscopy were assessed fully recovered at PADSS score 10. Patients with prolonged recovery were admitted to the ward for an overnight stay. Patient-reported outcome measures (PROM) after ERCP were nausea or vomiting, pain and/or fatigue, measured with a visual analogue scale (VAS, $0=$ none and $100=$ the worst experienced). PROM was further evaluated with questionnaires, the Post-Discharge Surgical Recovery scale (PSR) (21) (Supplemental 1) and the Quality of Recovery-23 (QoR-23) (22) (Supplemental 2), which were distributed to follow up patient recovery the first day after bronchoscopy.

Children after procedure completion were evaluated regarding recovery according to the UMSS and were assessed as fully recovered when obtaining a score of 0 combined with stable cardiorespiratory function.

\section{Endoscopists and patient-reported experience measures}

The procedure feasibility was assessed by the endoscopists after completion of the procedure. In Study I this was done by the Endoscopist's Assessment of Procedure Scale (73) (Table 8), whereby a lower score indicates better conditions to perform the endoscopy. Study II used a study-specific instrument to evaluate the bronchoscopist's perception of cough, bronchial secretion, feasibility and patient movement during the procedure. The assessment used a Likert scale of "Very dissatisfied" (1), "Dissatisfied" (2), "Neither dissatisfied nor satisfied" (3), "Satisfied" (4) or "Very satisfied" (5). Patients with unresolved discomfort or inability to co-operate, due to insufficient sedation after additional rescue medication, which affected the procedure feasibility, resulted in an inability to 
continue the procedure. Patients with aborted and failed procedures in the control group of Study I repeated the procedure with PCS.

Patient-reported experience measures were post-procedural overall satisfaction, measured with a visual analogue scale (VAS, $0=$ none and $100=$ the worst experienced) when patients were fully recovered after the procedure. Patient satisfaction measurement contained one open question regarding preferences for the type of sedation if needed in the future (Study I). The overall patient satisfaction was in Study II evaluated with a study-specific instrument (Likert scale): "Very dissatisfied" (1), "Dissatisfied" (2), "Neither dissatisfied nor satisfied" (3), "Satisfied" (4) or "Very satisfied" (5).

The feasibility of the wound care procedure (Study IV) was evaluated using a study-specific instrument. The scores were as follows: "can perform the procedure in the usual way" (1), "can perform the procedure with some affected access (mode, movements)" (2), "can perform the procedure with affected access and greater effort" (3), and "failure to complete the procedure satisfactorily" (4). 
Table 8.

\begin{tabular}{|c|c|c|}
\hline \multicolumn{3}{|l|}{ Endoscopist's assessment of procedure } \\
\hline & & Points \\
\hline Ease of introduction of endoscope & $\begin{array}{l}\text { Easy } \\
\text { Mild difficulty } \\
\text { Difficult } \\
\text { Extremely difficult }\end{array}$ & $\begin{array}{l}1 \\
2 \\
3 \\
4\end{array}$ \\
\hline Patient co-operation during procedure & $\begin{array}{l}\text { Very good } \\
\text { Good } \\
\text { Average } \\
\text { Minimal }\end{array}$ & $\begin{array}{l}1 \\
2 \\
3 \\
4\end{array}$ \\
\hline Retching/vomiting & $\begin{array}{l}\text { None } \\
\text { Minimal } \\
\text { Moderate } \\
\text { Marked }\end{array}$ & $\begin{array}{l}1 \\
2 \\
3 \\
4\end{array}$ \\
\hline Cough & $\begin{array}{l}\text { None } \\
\text { Minimal } \\
\text { Moderate } \\
\text { Marked }\end{array}$ & $\begin{array}{l}1 \\
2 \\
3 \\
4\end{array}$ \\
\hline Belching & $\begin{array}{l}\text { None } \\
\text { Minimal } \\
\text { Moderate } \\
\text { Marked }\end{array}$ & $\begin{array}{l}1 \\
2 \\
3 \\
4\end{array}$ \\
\hline Defence reaction & $\begin{array}{l}\text { None } \\
\text { Minimal } \\
\text { Moderate } \\
\text { Marked }\end{array}$ & $\begin{array}{l}1 \\
2 \\
3 \\
4\end{array}$ \\
\hline
\end{tabular}

\section{Costs of sedation}

The cost-analysis in Study III was based on results from studies I and II. These data were converted to a monetary value by using unit costs for items and per minute cost for personnel according to mean monthly salaries, and multiplied with the frequency or time. Direct costs included costs for material and drugs, costs for personnel during the procedure, and costs for repeated procedures and unplanned hospitalisation due to insufficient sedation. Patients who are hospitalised incur indirect costs, depending on age, for lost production or unpaid work. No data was available according to the patients' occupations (employed, sick leave or retired) or monthly incomes. The mean monthly salary was obtained from the Swedish official statistics. For individuals $<65$ years of age, the mean monthly salary was multiplied by 1.54 to include the social benefits regulated by Swedish law, divided by 165 hours per month and multiplied by 8 hours (approximate workday) to calculate the cost per day (excluding weekends). As 
the age of retirement is 65 years in Sweden, individuals $\geq 65$ years had the cost of unpaid work related to i.e. household work or caring for children instead of lost production. For these individuals, the cost of lost production per day was multiplied by 0.35 , following the findings of earlier studies (74-76).

\section{Statistical analysis}

Statistical tests used in Study I, II and IV are presented in Table 9. Before initiation of analysis, the distribution of data was controlled to select adequate statistical analysis. An alpha of 0.05 was used for all tests as the cutoff for significance. Data from Study I and II were extracted to perform cost-analysis calculations in Study III, and values (number of items and time) were converted to a monetary value.

Statistical analysis was performed with Statistica version 10 (StatSoft Inc., Tulsa, OK, USA) (Study I), GraphPad Prism version 7 (GraphPad Software, La Jolla, USA) (Studies II and IV) or IBMC SPSSC Statistics version 25 (International Business Machines Corp., New York, USA). ClinCalc.com, Sample Size Calculator (https://clincalc.com/Stats/SampleSize.aspx, accessed 21 February 2019) or G*Power version 3.1.9.3 (Heinrich-Heine-Universität Düsseldorf, Germany) were used for sample size calculations. Excel 2010 (Microsoft Corporation (C) was used as the database and to organise data from case report forms. 


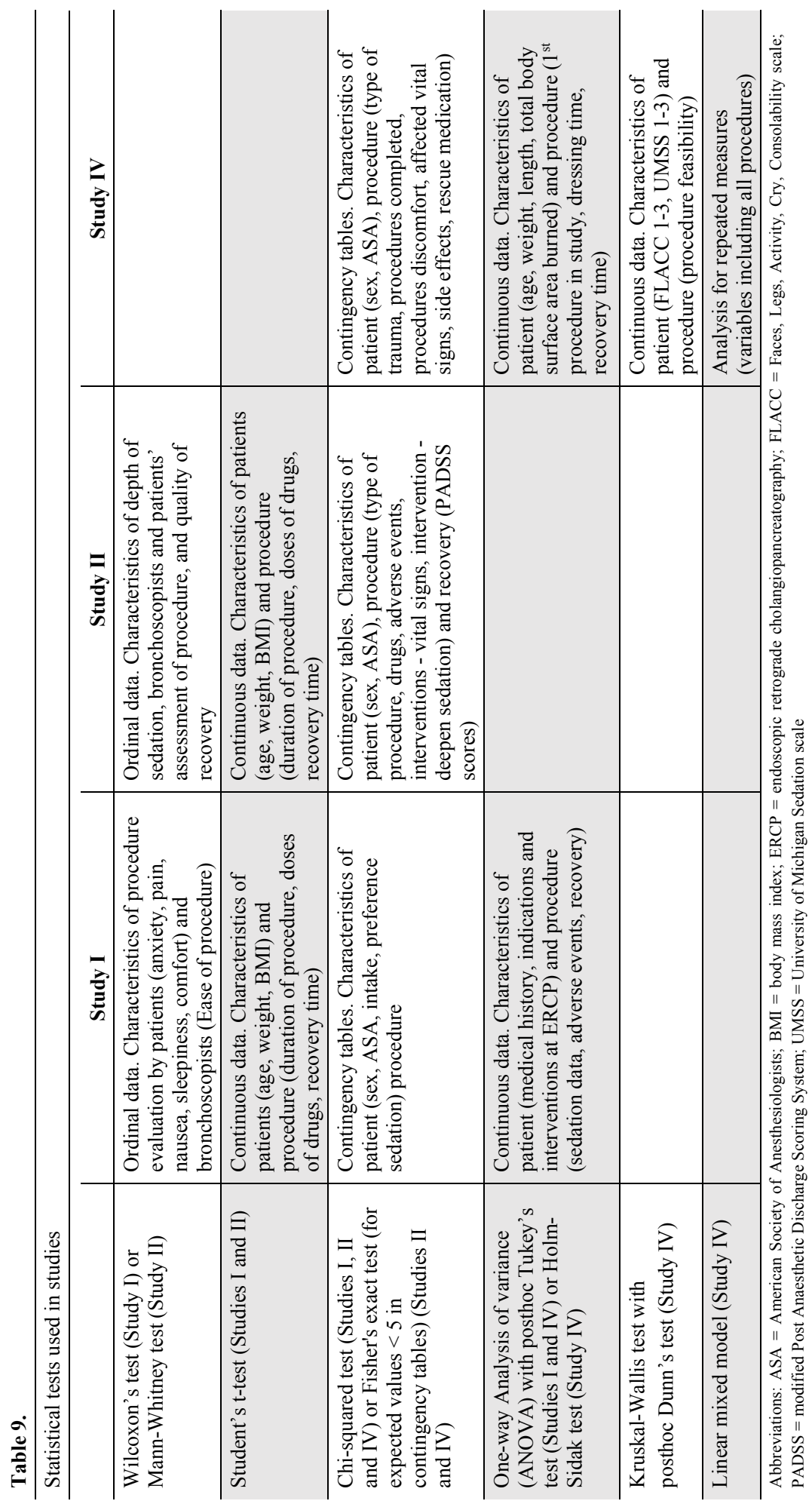




\section{RESULTS}

\section{Study I}

A total of 281 patients participated in the study, which included 301 ERCP procedures. Results are shown in Table 10. Patients in the control group had the lowest procedure feasibility, and 20 of 100 procedures needed to be aborted due to insufficient sedation. They were successfully repeated using PCS. Four percent $(n=4)$ of the patients in the PCS group needed additional propofol to proceed and complete the procedure. Cardiorespiratory events were few in the PCS group. The ACS group had significantly higher consumption of propofol, frequency of deep sedation and respiratory events. Hypotension was most frequent in the control group. The feasibility, measured as the ease of performing the ERCP by the endoscopist, was significantly increased by using propofol compared with midazolam.

Table 10.

\begin{tabular}{l|c|c|c|c}
\hline Procedure, sedation and cardiorespiratory data & $\begin{array}{c}\text { ACS } \\
(n=100)\end{array}$ & $\begin{array}{c}\text { PCS } \\
(n=101)\end{array}$ & $\begin{array}{c}\text { Control } \\
(n=100)\end{array}$ & $p$-value \\
\hline Duration of ERCP (min) & $40(26-59)$ & $30(19-44)$ & $32(19-58)$ & 0.065 \\
\hline Ease of ERCP (score) & $11.1 \pm 3.8$ & $8.3 \pm 2.5^{1}$ & $7.2 \pm 2.6^{2}$ & $<0.001$ \\
\hline Insufficient sedation & 20 & 4 & $0^{3}$ & $<0.001$ \\
\hline Sedation OAA/S level 2 & 2 & 4 & 39 & $<0.001$ \\
\hline Desaturation (SpO $<90 \%)$ & 4 & 2 & 10 & 0.034 \\
\hline Semi-obstructed airway (snoring) & 1 & 3 & 25 & $<0.001$ \\
\hline Hypotension (SBP $<80 \mathrm{mmHg})$ & 8 & 1 & 4 & 0.038 \\
\hline Bradycardia (HR $<40 \mathrm{bpm})$ & 0 & 1 & 0 & 1.000 \\
\hline Vomiting & 2 & 4 & 1 & 0.365 \\
\hline $\begin{array}{l}\text { Doses of sedatives (mg): } \\
\text { induction }\end{array}$ & $4.2 \pm 1.4$ & $236 \pm 133$ & $337 \pm 255$ & $<0.001^{4}$ \\
total dose & & $0.053 \pm 0.038$ & $0.083 \pm 0.053$ & $<0.001^{4}$ \\
\hline mg/kg/minute & & $75 \pm 29$ & $79 \pm 66$ & 0.523 \\
\hline
\end{tabular}

Differences reported are between the three groups. Data are presented as median (inter quartile range), mean \pm standard deviation, number of observations

${ }^{1} \mathrm{PCS}$ versus control, $p<0.001 ;{ }^{2} \mathrm{PCS}$ versus ACS, $p=0.022 ;{ }^{3} \mathrm{PCS}$ versus ACS, $p=0.044 ;{ }^{4}$ between the propofol groups Abbreviations: $\mathrm{ACS}=$ nurse anaesthetist-controlled sedation; $\mathrm{BPM}=$ beats per minute; $\mathrm{ERCP}=$ endoscopic retrograde cholangiopancreatography; HR = heart rate ; OAA/S = Observer's Assessment of Alertness/Sedation Scale; PCS = patientcontrolled sedation; $\mathrm{SBP}=$ systolic blood pressure; $\mathrm{SpO}_{2}=$ blood oxygen saturation 
The recovery period was significantly shorter for PCS compared with other groups, but all patients were assessed fully recovered (Aldrete $\geq 9$ ) within 90 minutes after completion of the procedure. Further recovery details are presented in Table 11.

Table 11.

\begin{tabular}{l|c|c|c|c}
\hline Recovery after completed procedure & $\begin{array}{c}\text { Control } \\
(n=100)\end{array}$ & $\begin{array}{c}\text { PCS } \\
(n=101)\end{array}$ & $\begin{array}{c}\text { ACS } \\
(n=100)\end{array}$ & $p$-value \\
\hline Early recovery period, Alderete $\geq 7(\mathrm{~min})$ & $10 \pm 6.6$ & $10 \pm 7.1$ & $10 \pm 3.9$ & 0.152 \\
\hline Recovery period, Alderete $\geq 9(\mathrm{~min})$ & $18 \pm 22.7^{1}$ & $12 \pm 13.6$ & $32 \pm 21.1^{2}$ & $<0.001$ \\
\hline Fully recovered & & & & \\
\hline After completion of ERCP & $84^{3}$ & 63 & $29^{4}$ & $<0.001$ \\
\hline At arrival on ward & 92 & 95 & 90 & 0.565 \\
\hline 30 minutes after arrival on ward & 95 & 100 & 96 & 0.198 \\
\hline 60 minutes after arrival on ward & 100 & 101 & 100 & 1.000 \\
\hline
\end{tabular}

Data are presented as mean \pm standard deviation and number of patients fully recovered (Aldrete $\geq 9$ )

${ }^{1} \mathrm{PCS}$ versus control, $p<0.001 ;{ }^{2} \mathrm{PCS}$ versus ACS, $p<0.001 ;{ }^{3} \mathrm{PCS}$ versus control, $p=0.027 ;{ }^{4} \mathrm{PCS}$ versus ACS, $p<0.001$

Abbreviations: ACS $=$ nurse anaesthetist-controlled sedation; ERCP $=$ endoscopic retrograde cholangiopancreatography; $\mathrm{PCS}=$ patient-controlled sedation

Patients with propofol sedation had the least post-procedural pain and sleepiness, and the highest overall satisfaction and would to a greater extent choose the same type of sedation if they needed to repeat the procedure. Further details regarding the patients' evaluation are presented in Table 12. 
Table 12.

\begin{tabular}{l|c|c|c|c}
\hline Patients' evaluation of the procedure & $\begin{array}{c}\text { Control } \\
(n=100)\end{array}$ & $\begin{array}{c}\text { PCS } \\
(n=101)\end{array}$ & $\begin{array}{c}\text { ACS } \\
(n=100)\end{array}$ & $p$-value \\
\hline Pre-procedure anxiety & $31(24-39)$ & $32(26-39)$ & $27(20-33)$ & 0.481 \\
\hline Per-procedure anxiety & $40(32-50)^{1}$ & $19(14-23)$ & $12(7-16)^{2}$ & $<0.001$ \\
\hline Per-procedure pain & $29(22-37)^{3}$ & $14(10-18)$ & $8(4-11)^{4}$ & $<0.001$ \\
\hline Post-procedural pain & $27(20-34)^{5}$ & $15(10-21)$ & $18(12-25)^{6,7}$ & 0.032 \\
\hline Post-procedural nausea & $13(8-19)$ & $7(4-11)$ & $8(4-12)$ & 0.124 \\
\hline Post-procedural sleepiness & $55(43-63)^{8}$ & $32(26-37)$ & $45(37-53)^{9}$ & $<0.001$ \\
\hline Overall experienced procedure comfort & $65(39-72)^{10}$ & $84(79-88)$ & $90(87-93)^{11}$ & $<0.001$ \\
\hline Able to eat within 4 hours (yes/no), $\mathrm{n}^{12}$ & $50 / 12$ & $67 / 7$ & $57 / 9$ & $<0.001$ \\
\hline $\begin{array}{l}\text { Preference for the sedation } \\
\text { if repeated ERCP (yes/no), } \mathrm{n}^{13}\end{array}$ & $42 / 23$ & $72 / 3$ & $66 / 2^{14}$ & $<0.001$ \\
\hline
\end{tabular}

Data is presented as mean (CI) according to VAS or number of answers

${ }^{1} \mathrm{PCS}$ versus control, $p<0.001 ;{ }^{2} \mathrm{PCS}$ versus ACS, $p=0.21 ;{ }^{3} \mathrm{PCS}$ versus control, $p<0.001 ;{ }^{4} \mathrm{PCS}$ versus ACS, $p=0.35 ;{ }^{5} \mathrm{PCS}$ versus control, $p<0.001 ;{ }^{6} \mathrm{PCS}$ versus $\mathrm{ACS}, p=0.201 ;{ }^{7} \mathrm{ACS}$ versus control, $p=0.21 ;{ }^{8} \mathrm{PCS}$ versus control, $p<0.001 ;{ }^{9} \mathrm{PCS}$ versus ACS $p<0.04 ;{ }^{10} \mathrm{PCS}$ versus control; $p<0.001 ;{ }^{11} \mathrm{PCS}$ versus ACS $p=0.19 ;{ }^{12} \mathrm{All}$ patients were not always allowed to eat. Those who were allowed: $90 / 101$ in the PCS group, 86/100 in the control group and 80/100 in the ACS group. ${ }^{13}$ This question was not always answered. ${ }^{14} \mathrm{PCS}$ versus $\mathrm{ACS} ; p=0.731$

Abbreviations: ACS = nurse anaesthetist-controlled sedation; ERCP = endoscopic retrograde cholangiopancreatography; PCS = patient-controlled sedation; VAS = visual analogue scale

\section{Study II}

A total of 150 patients underwent bronchoscopic procedures. The proportion of patients ready for discharge after 2 hours (PADSS score 10) was significantly greater for the combined PCS groups (81\%) compared with the control group $(40 \%, p<0.0001)$ and could further be improved by using glycopyrronium $(96 \%)$ instead of morphine-scopolamine $(65 \%, p=0.0002)$ as premedication (Table 13). Regardless of the premedication, PCS had the fastest recovery time at every measured time-point post procedure. The prolonged recovery time caused by midazolam (control group) rendered the need for overnight hospital stays in $10 \%$ of the cases.

PCS led to deeper sedation, and a few interventions were needed to ensure stable vital signs. One of 100 (1\%) of the patients using PCS had a drug-related adverse event compared with 5 of 50 (10\%) for those with midazolam (Table 14).

All procedures could be performed with high procedural feasibility and patient satisfaction with no differences between the groups, and the quality of recovery did not differ between the groups (Table 13). 


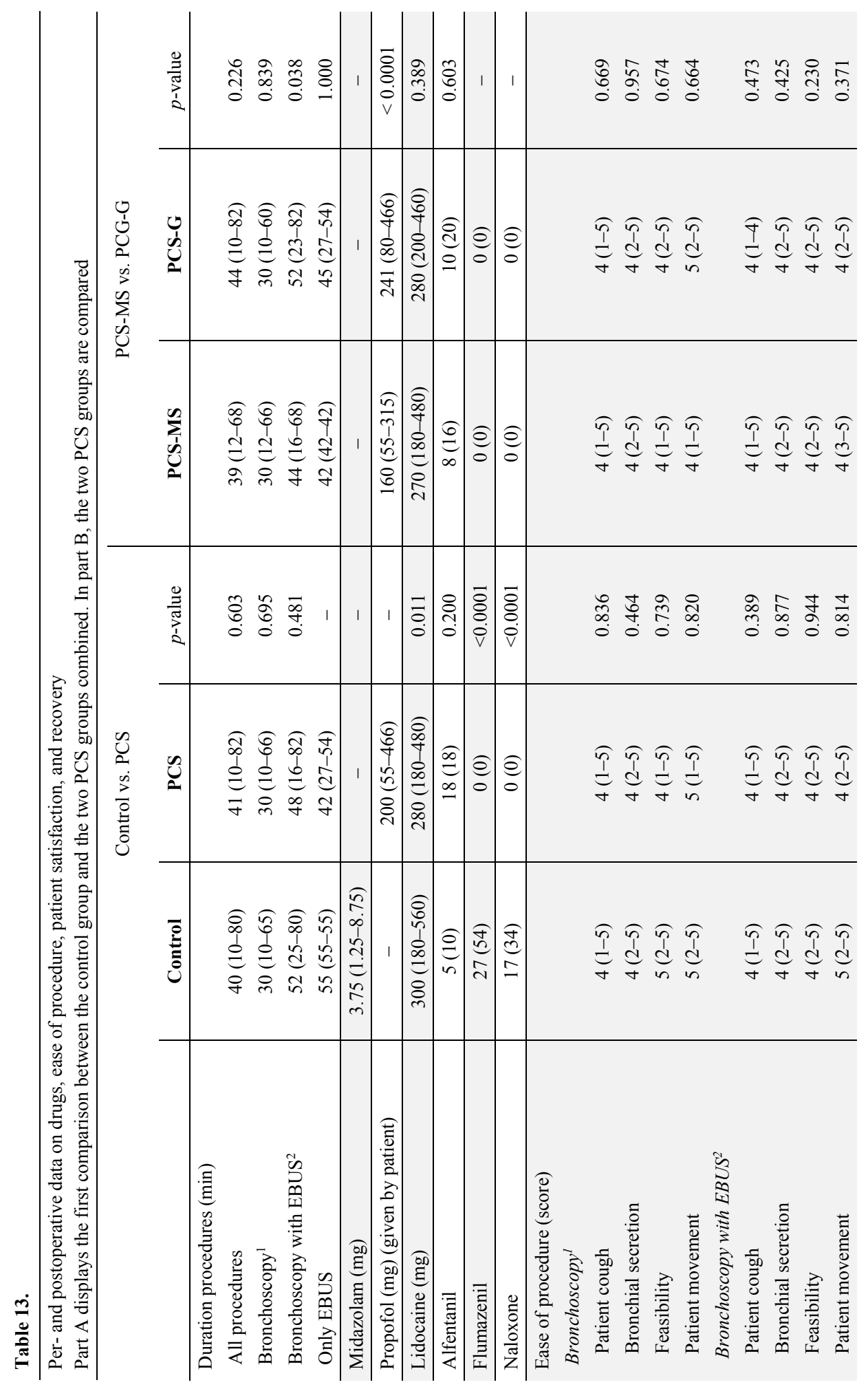




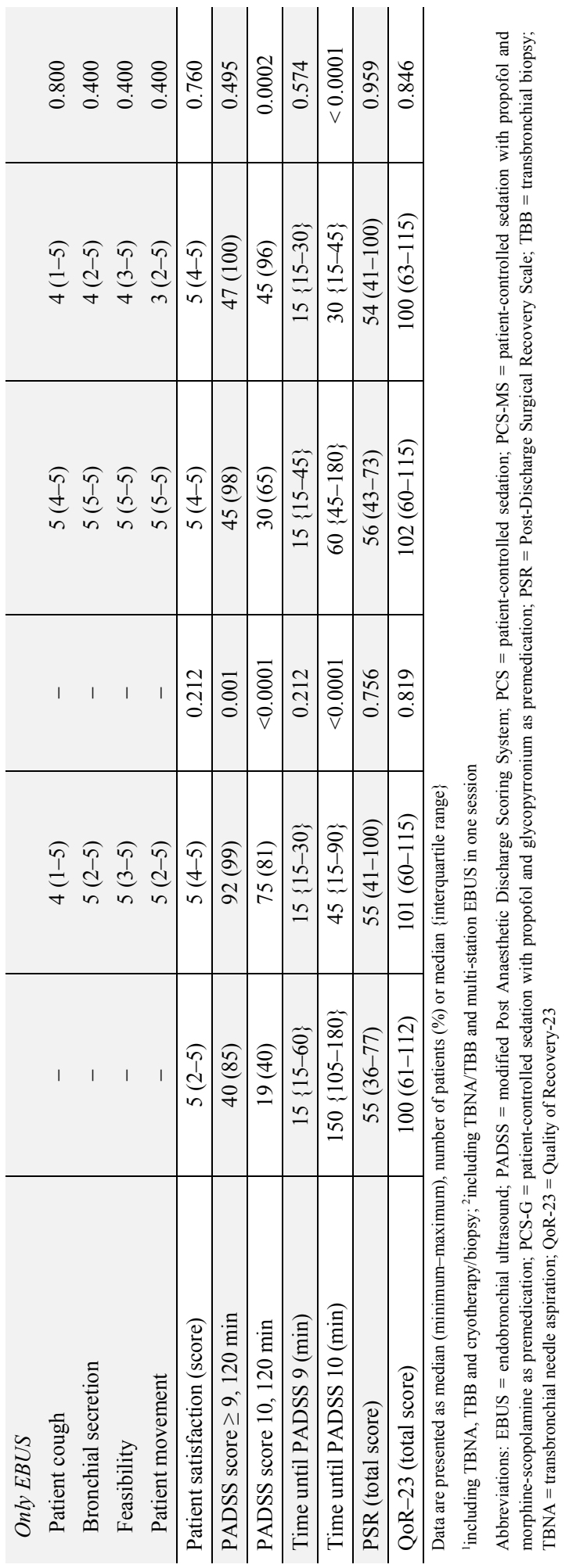




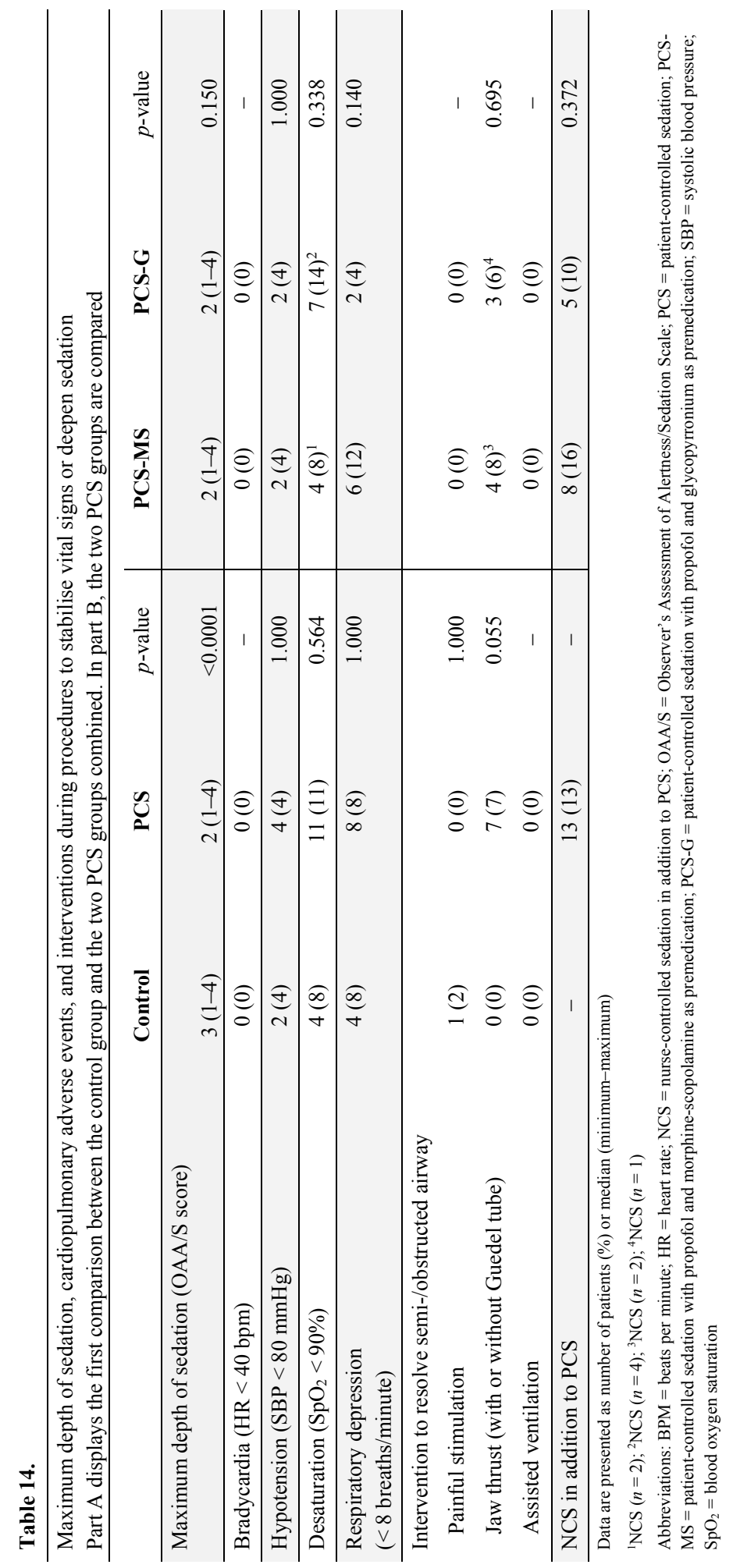




\section{Study III}

Propofol sedation with a bedside nurse anaesthetist with or without PCS during endoscopy in Study I and II resulted in the lowest direct costs compared to the control group (Table 15).

The direct costs for materials and medication are minor, regardless of the type of sedation that was used. Propofol sedation rendered an increased cost for anaesthesia personnel. The most dominant cost item was repeated procedure with additional days at the hospital and the costs for additional sedation (Study I), and prolonged recovery with need for overnight hospitalisation (Study II), which led to increased indirect costs (Studies I and II) (Tables 16 and 17). PCS has the potential to trigger great cost savings (Table 18) and reduce direct costs for ERCP and FB procedures, primarily due to a reduction in aborted procedures. 


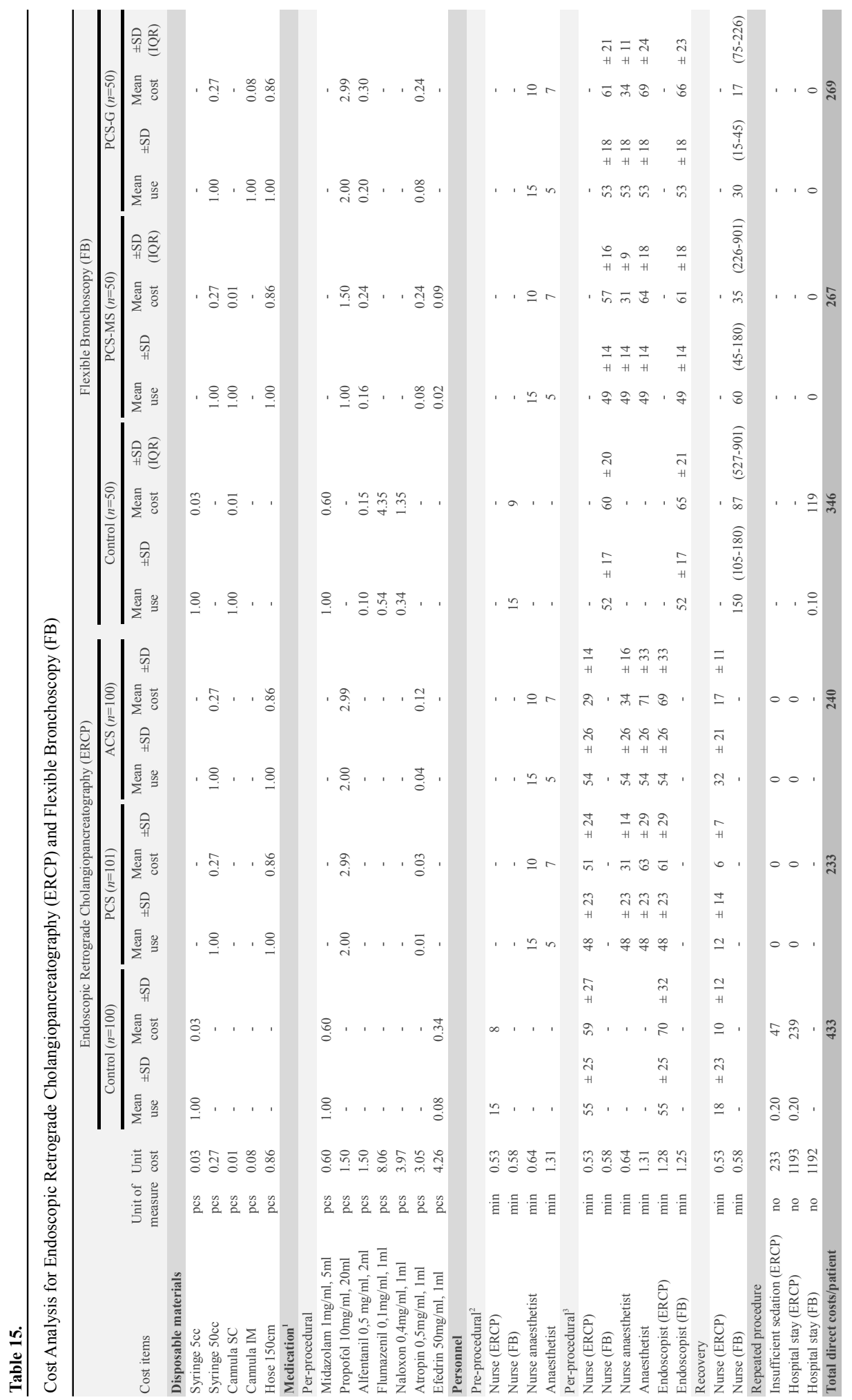




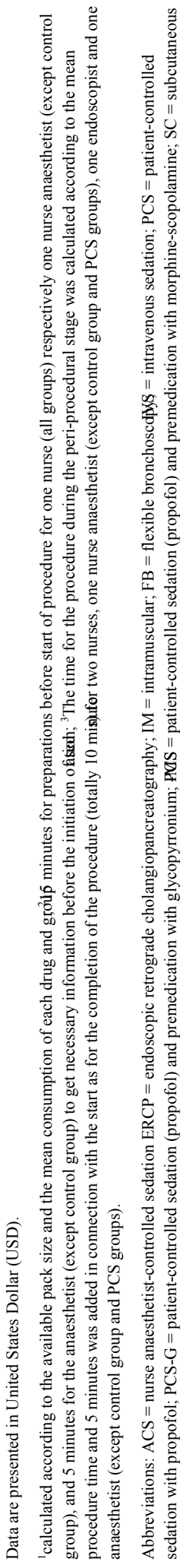


Table 16.

Indirect costs for endoscopic retrograde cholangiopancreatography (ERCP)

\begin{tabular}{l|c|c|c}
\hline & $\begin{array}{c}\text { Control } \\
(n=100)\end{array}$ & $\begin{array}{c}\text { PCS } \\
(n=101)\end{array}$ & $\begin{array}{c}\text { ACS } \\
(n=100)\end{array}$ \\
\hline Production loss $(<65$ years $)$ & 23 & 0 & 0 \\
\hline Unpaid work $(\geq 65$ years $)$ & 33 & 0 & 0 \\
\hline Indirect costs/patient & 56 & 0 & 0 \\
\hline
\end{tabular}

Data are presented in United States Dollar (USD)

Abbreviations: ACS = nurse anaesthetist-controlled sedation; PCS = patient-controlled sedation with propofol

Table 17.

Indirect costs for flexible bronchoscopy $(\mathrm{FB})$

\begin{tabular}{l|c|c|c}
\hline & $\begin{array}{c}\text { Control } \\
(n=50)\end{array}$ & $\begin{array}{c}\text { PCS-MS } \\
(n=50)\end{array}$ & $\begin{array}{c}\text { PCS-G } \\
(n=50)\end{array}$ \\
\hline Production loss $(<65$ years $)$ & 5 & 0 & 0 \\
\hline Unpaid work $(\geq 65$ years $)$ & 8 & 0 & 0 \\
\hline Indirect costs/patient & 14 & 0 & 0 \\
\hline
\end{tabular}

Data are presented in United States Dollar (USD).

Abbreviations: PCS-G = patient-controlled sedation (propofol) and glycopyrronium as premedication; PCS-MS = patient-controlled sedation (propofol) and morphine-scopolamine as premedication

Table 18.

Cost-savings during endoscopic retrograde cholangiopancreatography (ERCP) and flexible bronchoscopy (FB)

\begin{tabular}{l|c|c|c|c|c|c}
\multicolumn{2}{c}{} & \multicolumn{3}{c}{ ERCP } & \multicolumn{3}{c}{ FB } \\
\cline { 2 - 8 } & Control & PCS & ACS & Control & PCS-MS & PCS-G \\
\hline Direct costs/patient & 433 & 233 & 240 & 346 & 267 & 269 \\
\hline Cost savings/patient & - & 200 & 192 & - & 79 & 77 \\
\hline Annual cost savings $^{1}$ & - & 59981 & 57680 & - & 23641 & 23154 \\
\hline
\end{tabular}

Data are presented United States Dollar (USD).

${ }^{1}$ Based on 300 patients/year

Abbreviations: $\mathrm{ACS}=$ nurse anaesthetist-controlled sedation; ERCP $=$ endoscopic retrograde cholangiopancreatography; FB $=$ flexible bronchoscopy; PCS = patient-controlled sedation with propofol; PCS-G = patient-controlled sedation (propofol) and glycopyrronium as premedication; PCS-MS = patient-controlled sedation (propofol) and morphine-scopolamine as premedication 


\section{Study IV}

90 children were randomised into one of three dosing groups of racemic ketamine and completed 201 burn wound procedures. The total body surface areas burned (TBSA) were between 0.5 and $6.3 \%$, caused primarily through scalding or contact with heated objects. Not all children completed three consecutive procedures. Those who were completely healed or needed no further procedural sedation underwent one or two wound care procedures.

The maximum mean FLACC scores were low regardless of the ketamine dose. Eight $\mathrm{mg} / \mathrm{kg}$ resulted in deeper sedation, hypersalivation and prolonged recovery. Procedure feasibility was affected for children using the lower dose. Significantly fewer children had tachycardia when administered $6 \mathrm{mg} / \mathrm{kg}$. Only a few children needed supplemental sedation. The common factors among these children were FLACC $>3$ and affected feasibility (score $>1$ ) (Table 19).

One adverse event with laryngospasm occurred in the group administered 8 $\mathrm{mg} / \mathrm{kg}$.

Table 19.

\begin{tabular}{l|c|c|c|c}
\hline Per- and postprocedural data & $\begin{array}{c}\text { K-4 } \\
(n=69)\end{array}$ & $\begin{array}{c}\text { K-6 } \\
(n=64)\end{array}$ & $\begin{array}{c}\text { K-8 } \\
(n=68)\end{array}$ & $p$-value \\
\hline & $0(0-2)$ & $0(0-1)$ & $0(0-1)$ & 0.079 \\
\hline Maximum FLACC $(0-10)$ & $0(0-2)$ & $0(0-1)$ & $0(0-2)$ & 0.512 \\
All procedures & $0(0-2)$ & $0(0-1)$ & $0(0-0)$ & 0.084 \\
$1^{\text {st }}$ procedure & $0(0-2)$ & $0(0-0)$ & $0(0-0)$ & 0.355 \\
$2^{\text {nd }}$ procedure & 6 & 1 & 6 & 0.255 \\
$3^{\text {rd }}$ procedure & & & & \\
\hline Procedures with FLACC $>3(n)$ & $2(1-2)^{\dagger \dagger \dagger}$ & $2(1-2)$ & $2(2-2)^{\#}$ & $<0.0001$ \\
\hline Maximum UMSS $(0-4)$ & $2(1-2)^{\dagger}$ & $2(1-2)$ & $2(2-3)$ & 0.030 \\
All procedures & $1(1-2)^{\dagger}$ & $2(1-2)$ & $2(2-2)$ & 0.011 \\
$1^{\text {st }}$ procedure & $1(1-2)$ & $2(1-2)$ & $2(2-2)$ & 0.081 \\
$2^{\text {nd }}$ procedure & & & & \\
$3^{\text {rd }}$ procedure & 2 & 0 & 0 & - \\
\hline Procedures with affected vital signs $(n)$ & 0 & 0 & 0 & - \\
Bradycardia & 3 & 3 & 5 & 0.693 \\
Desaturation & $22^{*}$ & 10 & $22^{\#}$ & 0.066 \\
Respiratory depression & & & & \\
Tachycardia & 0 & 0 & $3^{\# \dagger}$ & - \\
\hline Procedures with side effects $(n)$ & & 1 & 1.000 \\
Hypersalivation & & & & \\
Postprocedural vomiting & & & & \\
\hline & & & & \\
\hline
\end{tabular}




\begin{tabular}{l|c|c|c|c}
\hline Procedures with rescue medication $(n)$ & & & & \\
$\mathrm{N}_{2} \mathrm{O} / \mathrm{O}_{2}$ & 1 & 0 & 1 & - \\
$\mathrm{N}_{2} \mathrm{O} / \mathrm{O}_{2}$ and Sevoflurane & 0 & 0 & 2 & - \\
Propofol & 1 & 0 & 0 & - \\
\hline Dressing time (min) & $31 \pm 7$ & $30 \pm 6$ & $31 \pm 8$ & 0.886 \\
$1^{\text {st }}$ procedure & $33 \pm 7$ & $31 \pm 5$ & $33 \pm 9$ & 0.491 \\
$2^{\text {nd }}$ procedure & $31 \pm 7$ & $31 \pm 8$ & $30 \pm 6$ & 0.730 \\
$3^{\text {rd }}$ procedure & $29 \pm 6$ & $28 \pm 5$ & $29 \pm 5$ & 0.898 \\
\hline Procedure feasibility $(1-4)$ & $1(1-2)^{* \dagger}$ & $1(1-1)$ & $1(1-1)$ & 0.010 \\
\hline Recovery time & & & & \\
All procedures (min) & $25 \pm 15^{\dagger \dagger}$ & $27 \pm 20$ & $36 \pm 22^{\#}$ & 0.010 \\
$1^{\text {st }}$ procedure & $27 \pm 15^{\dagger}$ & $35 \pm 24$ & $45 \pm 27$ & 0.018 \\
$2^{\text {nd }}$ procedure & $23 \pm 13$ & $22 \pm 14$ & $31 \pm 15$ & 0.059 \\
$3^{\text {rd }}$ procedure & $22 \pm 17$ & $23 \pm 9$ & $26 \pm 9$ & 0.764 \\
\hline
\end{tabular}

Data are presented as mean $\pm \mathrm{SD}$ or median (IQR)

K-4 versus K-6: * ${ }^{*}<0.05 ; \mathrm{K}-6$ versus K-8: \# $\mathrm{p}<0.05 ; \mathrm{K}-4$ versus K-8: $\uparrow \mathrm{p}<0.05, \dagger \dagger \mathrm{p}<0.01, \uparrow \dagger \mathrm{p}<0.0001$

Abbreviations: FLACC $=$ Face, Legs, Activity, Cry, Consolability behavioural pain scale; K-4 = Ketamine $4 \mathrm{mg} / \mathrm{kg}$; K-6 = Ketamine $6 \mathrm{mg} / \mathrm{kg} ; \mathrm{K}-8=$ Ketamine $8 \mathrm{mg} / \mathrm{kg} ; \mathrm{N}_{2} \mathrm{O} / \mathrm{O}_{2}=$ Nitrous oxide/Oxygen; UMSS = University of Michigan Sedation Scale 


\section{DISCUSSION}

\section{Procedural sedation}

\section{Safety}

The safety for PCS was evaluated in Studies I and II using surrogate variables in terms of affected vital signs and interventions to stabilise cardiorespiratory functions. The studies' size was limited, and conclusions regarding the safety should be drawn with this in mind. Few larger studies have been conducted to evaluate PCS with propofol during the last decade; most of them had a study population of less than 200 patients (28), and only one non-randomised study had a larger population ( $>1000$ patients) (77). One meta-analysis has been completed (28) showing that PCS with propofol significantly reduced the risk of sedationrelated rescue interventions, i.e. chin-lifts, bag-mask ventilations and drugs for treatment of hypotension or bradycardia, compared with propofol administered by clinicians.

In Study I, patients who were administered midazolam developed more frequently hypotension compared with PCS. Hypotension could not be seen in Study II. The risk for episodes of hypotension in an earlier meta-analysis favoured midazolam over propofol, but these conclusions were based on only three studies (78) with various definitions of hypotension (median arterial pressure $<60 \mathrm{mmHg},<90 \mathrm{mmHg}$ and $\geq 20 \%$ deviation from baseline). No conclusion regarding the risk for hypotension could be drawn in a recent metaanalysis due to small sample studies, but the trend seemed to favour PCS compared with clinician-controlled sedation (28) which is in line with another study (77).

The frequency of desaturation among patients with propofol was highest in the ACS group (Study I). Neither mode of propofol administration (28) nor drug (midazolam or propofol) seemed to influence the risk for desaturation during GI endoscopy (5) or bronchoscopy (78), except for one non-randomised study that showed a decreased incidence for PCS compared with anaesthesiologistadministered sedation (77). Of the complications related to the sedation, respiratory depression represented a third of all minor complications within colonoscopy (13).

In Study I propofol administered by a nurse anaesthetist led to higher frequency of deep sedation and interventions to solve an obstructed airway 
compared with PCS. Earlier studies found that the risk for cardiorespiratory adverse events, such as hypotension and airway obstruction, and oversedation increases when propofol administration is carried out by professionals instead of patients themselves using PCS (28). A recent meta-analysis showed that the person who administers propofol has a great impact on the development of sedation-associated minor and severe procedural or cardiorespiratory complications, whereby anaesthetist-provided sedation was associated with a higher risk compared to NAPS (13). It is unclear if the increased risk was due to the higher complexity of the procedures involving anaesthetists, however. Compared with previous studies which administered concomitant opioids (28), the median propofol doses in studies I and II were higher but still within similar dose ranges. The increased depth of sedation in the ACS group was probably caused by a higher dose of propofol as could be seen in Study I. In Study II an increased dose of propofol in one of the PCS groups did not affect the level of sedation. However, the possible synergistic effect of premedication with morphine-scopolamine makes direct comparison impossible.

Traditional sedatives used during GI endoscopy, in which the majority is midazolam, have been shown to have a similar risk to develop cardiorespiratory adverse events as propofol (79). In Study II, patients with PCS-administered propofol were assessed to have a deeper level of sedation compared with those given midazolam. These findings are difficult to confirm as there are only a few studies in the same setting measuring level of sedation, but results for ERCP procedures showed no difference between depths of sedation for these drugs (80).

In Study II, beside predefined interventions to preserve stable vital signs, we documented all other adverse events related to the study drugs. The results, although non-significant, showed that midazolam had a higher incidence of drugrelated events. The risk of developing sedation-associated complications is increased with the use of midazolam compared with propofol alone, according to results from a large meta-analysis on colonoscopy (13). The risk increased further when adding an opioid to midazolam, which was present not only as premedication but also as a rescue medication in Study II. To reduce the risk for postprocedural oversedation when both midazolam and opioids have been administered it is recommended to use antagonists to reverse the effect of the drugs (3). Both flumazenil and naloxone are agents with shorter duration of action than both midazolam and morphine (81). Due to unequal duration, patients need to be observed to ensure that no recurrence of sedation occurs. The advantage of using flumazenil is the shortened recovery time (82) and faster cognitive recovery after bronchoscopy (83). Disadvantages are common side effects such as anxiety, agitation, dizziness, hypertension and tachycardia (81). 
The finding of more adverse events, such as confusion, in the control group in Study II could be explained by the use of midazolam.

The type of planned intervention affects the duration of the procedure. ERCP (Study I) and bronchoscopy combined with biopsy, needle aspiration and/or endobronchial ultrasound (EBUS) (Study II) are more complex and advanced procedures in comparison with simpler diagnostic gastroscopy or bronchoscopy performed by an anaesthetist/intensivist. Procedure duration ( $\geq 10$ minutes) is one of the most prominent factors that increases the risk for sedation-associated complications (13). An ASA class 3 also increases the risk for complications related to sedation (13). Patients with ASA $>2$ made up almost half of all patients in Study II, which in our opinion examines today's limitation of what is possible with PCS and propofol.

\section{Effectiveness}

The time until patients were fully recovered (Aldrete $\geq 9$ ) after the ERCP procedure was shorter for PCS patients compared with both midazolam and ACS (Study I). Results from previous studies reveal that propofol has a faster recovery time than midazolam in both GI and bronchoscopic procedures $(26,84)$, not only in time but also regarding cognitive function (85). The findings in Study I of a prolonged early recovery in the ACS group is in this context contradictory. The method of propofol administration seemed to have an impact on recovery, probably because of the different doses of propofol.

In Study II, patients given propofol had the fastest recovery (PADSS score 10), whereby those premedicated with glycopyrronium recovered the quickest. Glycopyrronium as premedication and propofol as sedation during bronchoscopy in an earlier study proved effective to reduce recovery time compared with midazolam (85). Patients receiving premedication with an opioid reduced their dose of propofol significantly (Study II). The reduction of the total dose of propofol when adding an opioid has been confirmed in a previous study, but the combination did not, compared to our results in Study II, prolong recovery (86). Differences in recovery time can possibly be explained by the use of morphinescopolamine, which has an increased sedative effect due to the combination but also the mode of administration, intramuscular, which gives a slower release and longer duration.

In both clinical studies (Studies I and II), patients using the PCS had a lower incidence of post-procedural complications than those administered with midazolam. In Study I, pain and sleepiness were found to be significantly reduced by the use of propofol PCS compared with the control and ACS group. The reduced incidence of sleepiness is probably a factor contributing to the fast recovery in the PCS groups after procedure completion. Five patients who were 
administered midazolam in Study II needed to stay overnight due to the prolonged effect of the study drug. Confusion and agitation are well-known side effects for midazolam. When this occurs, it affects the health care system by unintended overnight stays, but also the patient with possible affected quality of life and an unplanned prolonged hospital stay.

Procedure feasibility is very important to ensure a safe and high-quality intervention to reliably diagnose or the possibility to perform a therapeutic intervention. Feasibility is dependent on several factors, including the ease of introducing the endoscope, cough and patient co-operation/movement, which are common for many endoscopic procedures. Some occur mostly in ERCP (belching/vomiting) and others during bronchoscopy (cough, bronchial secretion). The possibility to perform the procedure was highest for ACS followed by PCS and midazolam in Study I. The use of propofol seemed to affect procedural feasibility in a positive way. This conclusion was made earlier by Wehrmann, who showed that propofol increased not only patients' co-operation but also the ability to tolerate endoscopy during insertion and during the procedure (87). Overall assessment for all interventions during the procedures by the bronchoscopists showed high feasibility for all groups. Feasibility would probably have been affected and possibly lead to an aborted procedure for those few PCS patients where sedation was deepened by anaesthesia personnel. The feasibility can, according to our results, be improved if administration is handled by a nurse anaesthetist (Study I). In contrast to our findings a recent metaanalysis found no differences for operator satisfaction between different methods of propofol administration (28).

The abortion of procedures due to insufficient sedation is a failure which may give a short-term effect for the patient regarding a missed diagnosis or treatment for a condition. In Study I, 20\% of the patients receiving midazolam sedation were insufficiently sedated for the patient to be able to tolerate the endoscope and make the procedure feasible for the endoscopic team. These aborted procedures were repeated using PCS with propofol and were successfully completed without any additional sedation provided by the nurse anaesthestist, which strengthens the argument for the use of PCS as a sedation method. Four of 101 patients using PCS needed additional propofol to be administered by the nurse anaesthetist. A high proportion of procedures that could be performed without interruptions using PCS has been seen by others within the same context of ERCP (88). In Study II all bronchoscopies could be completed, but the bedside nurse anaesthestist had to intervene in $13 \%$ of the PCS cases using rescue administration of propofol, mostly due to the inability of the patient to co-operate and follow instructions during moments of increased procedural risks and upon request from the bronchoscopist to be completely still. 
In case of a repeated ERCP procedure in the future, most patients were positive towards to use PCS with propofol (Study I). Within the endoscopic field patient willingness has only been studied for colonoscopy, and similar were found in a large study by Lee (34). The most recent meta-analysis for colonoscopy, based on a few small studies with great heterogeneity, concluded that no differences could be detected between PCS and IVS regarding the patients' willingness to repeat the same sedation method (89).

Patient satisfaction was significantly higher for patients with propofol in Study I, which an earlier meta-nalysis (28) confirmed using the same instrument for measuring satisfaction. A study comparing propofol and midazolam showed a higher degree of satisfaction for midazolam than we have shown (90). Regardless of the type of sedation, satisfaction during endoscopy was high not only at the time of discharge but also when assessed later at home (90). The higher degree of satisfaction in that study could be because of easier intervention (colonoscopy) compared to the more difficult intervention of ERCP. In Study II we assessed the patients' health status and activity after discharge and also their emotional state, physical comfort and physical independence. The results from the questionnaires complement our previous findings that not only satisfaction is scored high but also that the physical and emotional state is high regardless of the type of sedation. These findings show that the type of sedation does not affect patients' quality of recovery after arrival at home.

\section{Costs}

The cost for health care increases each year for most countries in the European Union, and Sweden is one the countries with the highest cost per capita (91). The Swedish health care system, which mainly is decentralised and funded by the government through taxes, is challenged to deliver safe and effective health care. With scarce resources each county council, which is responsible for its residents, needs to prioritise and make decisions about which care should be delivered. It is crucial to choose a perspective when evaluating health economics since a cost from one point of view maybe is not a cost from another. These analytic perspectives may include one or more of the following: the individual patient, the target group for the specific procedure, the specific clinic, the county council, the governmental or the societal perspective (including a wider perspective) (92).

Sedation during diagnostic and therapeutic endoscopic procedures involves several different types of costs. We used a clinical perspective and included direct costs for material/drugs, personnel and additional costs due to difficulties with the sedation, but also indirect costs calculating the loss of production (societal perspective). 
There are few published cost-analyses within the field of PCS $(35,49)$. More data is needed as PCS has shown positive results with low drug consumption, rapid recovery and high feasibility.

The results for Study III are comparable to others in the sense that PCS rendered higher costs for materials and drugs compared with IVS (49). These costs are minor during ERCP and FB compared with other items calculated for direct costs. Using propofol in the context of our studies with a bedside nurse anaesthetist and anaesthesiologist available during the procedure vastly increased the costs compared with midazolam. The addition of costs for prolonged recovery with IVS and midazolam resulted in almost equal costs for personnel regardless of the method. For ERCP (Study I), the cost reduction of personnel during PCS was due to shorter procedures and recovery time. The shorter recovery using non-opioid premedication reduced the costs for recovery after bronchoscopy (Study II).

The costs involved to repeat the procedure due to insufficient sedation and the additional hospital stay is the most dominant cost item for the cost-analysis of Study I. Vargo expressed this thought earlier (50): it should be taken into consideration that PCS could potentially gain through its efficiency and offset the higher costs for the method. With $20 \%$ of the midazolam patients in need of another procedure increased costs for ERCP accounted for almost three quarters of the direct costs. Reducing the number of aborted procedures is a potential cost saving and was shown to be successful during PCS with bedside nurse anaesthestists in Studies I and II. Ten percent of the patients administered midazolam during bronchoscopy that needed to stay at the hospital after the procedure (Study II) rendered a high cost. These unplanned hospital stays were related to the study drug and can be avoided by using PCS with propofol. In relation to the economic analysis of Study I and II, Vargo was correct that the higher costs of PCS could be justified by its improved efficiency (50).

Even if the indirect costs for loss of production and unpaid work were minor and had limited impact on the total cost, they added a new perspective to the cost-analysis that has not been done before.

By exchanging the drug for sedation from midazolam to propofol the total cost for sedation can decrease significantly for both ERCP and bronchoscopy. The reduction in costs triggers great savings and an optimal use of monetary scarce resources but also increases the overall demand for anaesthesia personnel within the health care sector. Implementation of propofol sedation for various types of procedures could be easily done if anaesthesia personnel were available. In many scenarios this category of personnel is considered as a "scarce resource", which hinders the transition to change drug. By deploying non-anaesthesia personnel for propofol sedation scarce anaesthesia resources can be allocated and 
used for patients with more difficult conditions and in complex settings. The administration of propofol by trained non-anaesthesiologists has been shown to be performed safely $(23,24)$. Sedation with propofol PCS has been shown to be a safe alternative to sedation performed by a clinician in settings of PCS with bedside anaesthesia personnel $(28,35)$. Results from a study on colonoscopy concluded that costs for PCS were higher compared to nurse-administered propofol sedation despite the additional cost for the nurse (35). Our findings are not comparable due to the use of anaesthesia personnel during the sedations but add new knowledge for economic evaluation of sedation within health care. Endoscopic personnel responsible for midazolam sedation in today's setting could possibly after training supervise and assist the patient during propofol PCS. This scenario would need a start-up investment for training but might in the long run vastly reduce costs for personnel. For a few patients propofol was insufficient, and additional propofol was given by the nurse anaesthetist (Studies I and II). A combination of PCS and additional propofol given by nonanaesthetists could potentially increase cardiorespiratory risks for patients and has to our knowledge not been studied before. To abort these procedures with the need to repeat the procedure would increase the total cost for the method.

\section{Paediatric procedural sedation}

\section{Pain}

Rectal racemic ketamine regardless of dose combined with midazolam was effective in reducing pain in Study IV. Children receiving the lower dose had a trend of increased FLACC scores. Comparable studies measuring pain within the context of paediatric burn wound care using similar rectal doses of racemic ketamine and midazolam are lacking. A study on painful injections in children with cerebral palsy, which possibly is a less painful procedure, showed median FLACC levels of 2 (range 0-8) with high feasibility using a mean dose of 3.9 $\mathrm{mg} / \mathrm{kg}$ racemic ketamine combined with a mean dose of $0.26 \mathrm{mg} / \mathrm{kg}$ midazolam (93). Increasing the dose from 4 to $8 \mathrm{mg} / \mathrm{kg}$ with the addition of midazolam has been shown to give better pain relief but also deepen the level of sedation (61). Overall, all three doses gave adequate pain relief and good procedure feasibility but could further be improved using 6 or $8 \mathrm{mg} / \mathrm{kg}$. For the few children with FLACC $>3$ the randomised dose was insufficient to relieve pain $(4 \mathrm{mg} / \mathrm{kg}: 2$ children, $8 \mathrm{mg} / \mathrm{kg}$ : 3 children). The same procedures also affected procedure feasibility. In our study, a higher dose increased the depth of sedation and presence of known dose-related side effects. An increase of dose-related side effects could possibly increase the risk for agitation, which is a common side effect of racemic ketamine, and makes interpretation of pain using FLACC more 
difficult, which could result in interventions undertaken to reduce "pain". A child with pain interferes negatively with the wound care procedure and hinders procedure feasibility. We suggest that $4 \mathrm{mg} / \mathrm{kg}$ could be the lowest limit for procedures of similar length and involving similar level of pain.

\section{Safety}

In Study IV we showed that a dose of $6 \mathrm{mg} / \mathrm{kg}$ rectal racemic ketamine minimised the events with affected vital signs, side effects and need for rescue medication. There were however few events of affected vital signs and side effects, except for tachycardia. An increased heart rate is a common and wellknown side effect for racemic ketamine (94) and was seen in children administered both a lower and a higher dose (Study IV). A dose-response relationship with racemic ketamine and the presence of adverse effects, such as tachycardia, has been shown in an earlier study (95). If these results were applied to our findings, children receiving the lowest dose $(4 \mathrm{mg} / \mathrm{kg})$ would have had fewer incidences of tachycardia than those receiving $6 \mathrm{mg} / \mathrm{kg}$. This was not the case and could reflect insufficient sedation. In an earlier study, children receiving $4 \mathrm{mg} / \mathrm{kg}$ racemic ketamine compared to $8 \mathrm{mg} / \mathrm{kg}$ cried to a greater extent during IV cannulation (61). Similar results were found in Study IV where some children with the lowest dose were assessed to have more pain during the procedure. The above-mentioned study found, as we also did, that the level of sedation was dosedependent (61). The increased incidence of tachycardia and discomfort and lower UMSS scores for children with $4 \mathrm{mg} / \mathrm{kg}$ could possibly be a precursor for insufficient sedation or in the context of severely painful procedures, such as burn wound care, indicate that we were close to the lowest possible dose level with an insufficient dose to give adequate sedation and pain relief.

The small residual functional capacity with increased sensitivity to hypoxaemia can cause respiratory complications and an increased incidence of morbidity and mortality in the paediatric population during anaesthesia (96). We did not find that ketamine, regardless of dose, affected the respiratory system to an extent leading to desaturation $<90 \%$. Our results regarding racemic ketamine's respiratory safety have been confirmed in earlier studies $(61,97)$.

The combination of racemic ketamine and midazolam can be questioned. A study of over 6,000 children showed that concomitant use of both drugs increased the odds of a serious adverse event compared with ketamine alone (98). Other studies have not showed any significant differences in emergent reactions (agitation, delirium) between racemic ketamine alone or combined with midazolam $(59,99)$.

Compared to midazolam alone, the combination with racemic ketamine does not reduce oxygen saturation in the blood (100) but increases the risk for 
hypersalivation (97). Hypersalivation, which is a well-known and documented side effect of racemic ketamine (94), only occurred in children given $8 \mathrm{mg} / \mathrm{kg}$ (Study IV), whereby one child needed bag ventilation with mild overpressure and oxygen for saturation to be maintained above $>90 \%$. The presence of hypersalivation could result in an occluded airway with the risk of developing laryngospasm and desaturation (101). To reduce intraoral salivation during racemic ketamine sedation anticholinergic agents have been used (102). A recent meta-analysis comparing racemic ketamine and racemic ketamine with atropine showed no differences regarding desaturation or laryngospasm between the groups (103).

\section{Recovery}

The time to full recovery is reduced with a lower dose of racemic ketamine and midazolam (104). In study IV, the time until fully recovered, when all procedures in each group were combined, was shortest for children administered 4 and 6 $\mathrm{mg} / \mathrm{kg}$. The differences of approximately 10 minutes are in the context of clinical practice small, but show a dose-response relationship for recovery. By using the rectal route, recovery can be improved compared with IV administration (65). 
Procedural sedation - Aspects on methods, safety and effectiveness 


\section{Strengths and limitations}

\section{Study I}

A strength of the design in Study I was the possibility to compare not only two drugs, midazolam and propofol, but also two different methods of sedation, PCS with a bedside nurse anaesthetist and nurse anaesthestist-administered sedation. A double-blinded design would have given us the possibility to compare PCS and ACS without the possible bias from the nurse anaesthetist regarding given doses. Applying new methods of sedation (PCS or ACS) within Study I and II may have caused bias due to a learning effect through the studies. By conducting a pilot study the risk for such bias was lowered. A comparison between the standard sedation and new methods of sedation could also have given the control group a practical advantage. Due to practical limitations of shortage of personnel a full randomisation could not take place. Patients were initially scheduled to fixed weekdays, and randomisation to PCS or ACS took place for patients on Mondays or Tuesdays; Patients on Wednesday were given midazolam, which could result in a selection bias.

\section{Study II}

The design of Study II made it possible to compare two different drugs for sedation, midazolam and propofol; two drugs for premedication, morphinescopolamine and glycopyrronium; and two methods of sedation, IVS and PCS. If we had added a fourth group, nurse anaesthetist-administered propofol sedation, we could have made it possible to evaluate the effect of PCS per se on propofol sedation. Based on the earlier Study I, where results had shown advantages for PCS, we chose not to add the fourth group. We used single-blinding for premedication to minimise bias for the bronchoscopist's evaluation of the procedure. A double-blinding of the premedication would have been possible if external personnel could have been involved in the study. Blinding of the PCS as stated in Study I was not possible. A possible bias is the assessment of PADSS, which was undertaken by the same personnel also involved in the procedure.

\section{Study III}

The cost-analysis was based on data from Study I and II, and the abovementioned limitations for these studies also apply for Study III. To compare the standard sedation with a new method of sedation could have given the control group a practical advantage. We decided to calculate the cost for items that were 
found in the previous studies and add items that we found to be of interest for the decision-making at the clinic or hospital, and not use the fixed unit price for various procedures and interventions often used in Sweden. The selection of cost items did not include all costs for the endoscopic procedures and excluded costs, for example the administration to schedule/reschedule patients, pre-procedural test or samples, equipment wear and tear, facility costs or the intangible costs of the patient. All costs, and especially costs involved in a repeated procedure, are therefore likely underestimated.

\section{Study IV}

A strength in Study IV was the randomised and double-blinded design. We chose to randomise each child to one of the three racemic ketamine doses. This can be seen as a strength or a weakness. By repeating the same dose, we could minimise the influence from multiple variables (e.g. different areas with burns and variations in the degree of healed tissue) on the outcome measurements, but its weakness was the difficulty to detect dose-dependent intra-individual variability. By including a less-than-optimal dose level the present study may have evaluated and increased the odds of finding the optimal level in the evaluated dose range. Other limitations were the lack of evaluating inter-rater reliability for FLACC assessment between the involved nurse anaesthetists and that the decision to deepen sedation and use rescue medication was based on clinical experience and not pre-defined limits for FLACC and UMSS. 


\section{Clinical implications and future research}

The hypothesis and research questions in each study of this thesis were derived from clinical issues in daily practice, and upon completion have become either clinical practice or initiated a process to change the sedation strategy in Linköping University Hospital. The results are of importance for further research and generalisable to health care institutions with similar procedures, settings and clinical standards.

The introduction of a patient-controlled system instead of IVS with midazolam, which has been the standard care for decades, can be seen as a simplification or a challenge for the patient and the endoscopic team. The initiation of PCS for the procedures presented is, after a period of training and practice, simple in the sense that sedation is controlled, in the best of ways, by the patient and not the health care personnel. The challenge for the patient is to be introduced to the method and understand the essence of the PCS system to be able to manage the device and achieve the desired level of sedation to cope with the discomfort the procedure induces. For the endoscopic team the patient needs to be included as a member of the team. A successful "team-management" personnel interaction with the patient, and guidance through difficult sections of the procedure helps the patient to optimise the usage of PCS, reduce discomfort but also minimise interruptions during sensitive sections of the procedure.

The effectiveness of recovery for PCS using propofol compared with nurseadministered midazolam gives the possibility to facilitate procedures for outpatients later in the day without the need for an overnight stay and to increase the volume of patients undergoing the procedure during one day. For these scenarios to be possible, schedules for existing personnel need to be changed or additional personnel need to be hired to be able to carry out an increased number of procedures.

Procedures within the health care sector need to be effective. We have identified that sedation according to standard care during ERCP gives a high number of aborted procedures. These failed procedures affect not only the patient with unnecessary suffering and risks but also the provider by wasting scarce time and resources. PCS without a bedside nurse anaesthetist can be performed safely by non-anaesthesiologists according to earlier studies and our own experience, which would significantly reduce the amount of aborted procedures, repeated procedures and unplanned overnight hospital stays, resulting in improved effectiveness, which will benefit both patient and provider as well as society.

The PCS device has remained more or less unchanged since it was introduced over three decades ago. The development of new methods and 
algorithms within the concept of anaesthesia and TCI could possibly be of use also for PCS. By replacing the pre-defined and fixed bolus dose with algorithms based on sex, age, body weight and length, the PCS system might be further refined and more individualised regarding bolus dose, which possibly could improve outcome and reduce risks. This is an area for future research.

What influences the successful outcome of PCS from a patient's point of view? The answer to such a question could give valuable knowledge in the field of PCS and make improvements to the system easier. We know from earlier research that the sense of control has an impact on perceived pain, satisfaction and the willingness to use PCS again. Investigating the nature of psychology could identify other important variables to predict the success and outcome of PCS.

The racemic ketamine dose-finding study, which also derived from clinical issues, gives valuable knowledge for daily decision-making when choosing a suitable dose. The doses should be seen as references when rectal sedation is applied for children undergoing severely painful procedures. Rectal administration is easy to apply to infants and toddlers without the presence of IV lines. The traditional role for midazolam to lower side effects like hallucinations have been discussed and questioned. Further studies assessing recovery and psychological side effects during the first 48 hours could give valuable knowledge regarding the effects of these drugs. 


\section{CONCLUSIONS}

\section{General conclusions}

PCS with propofol has been shown to be a safe and effective alternative method of sedation. It offers stable cardiorespiratory conditions with few adverse events and interventions and a low risk for oversedation. Bedside anaesthetic personnel as a complement to PCS contribute to the successful execution of procedures. Recovery after PCS is swift and minimises the risk for prolonged hospitalisation. PCS is a potential cost saving method for sedation during endoscopic procedures.

By administering an optimal dose of rectal racemic ketamine, severely painful procedures can be performed safely with minimal risk for outbreaks of pain, without affecting procedure feasibility, along with rapid recovery.

\section{Specific conclusions}

\section{Study I}

- Propofol sedation is a favourable method for sedation compared with IVS and midazolam. PCS resulted in fewer respiratory events compared with ACS. Procedure feasibility was best in the ACS group followed closely by the PCS group. The control group had $20 \%$ aborted procedures due to insufficient midazolam sedation, which successfully could be performed on another occasion using PCS. All patients were fully recovered within one and a half hours after completion of procedure. Propofol sedation resulted in the least discomfort and greater patient preference to repeat the procedure with the same method in case of future ERCP procedures.

\section{Study II}

- Twice as many patients using PCS with propofol compared with IVS and midazolam were fully recovered (PADSS score 10) two hours after completion of the procedure.

- PCS with propofol resulted in few cardiorespiratory events, but sedation was deeper than IVS with midazolam. All procedures could be performed with high procedural feasibility and patient satisfaction with no differences between the groups. Recovery up to two hours was faster for PCS regardless of the time point of evaluation. The quality of recovery did not differ between the groups. 
- Rapid recovery was further increased by using glycopyrronium instead of morphine-scopolamine without affecting patient safety, procedure feasibility or patients' satisfaction.

\section{Study III}

- Propofol PCS with a bedside nurse anaesthetist is a cost saving method for sedation during ERCP and FB procedures compared with IVS and midazolam. The use of propofol sedation rendered increased direct costs for anaesthesia personnel. Costs for materials and medication were minor for all groups. Direct costs increased for patients with unplanned hospitalisation, and the most dominant cost item was the cost for repeated procedures with additional days at the hospital (ERCP) or prolonged stay with overnight admission (FB).

\section{Study IV}

A rectal-administered dose of $6 \mathrm{mg} / \mathrm{kg}$ compared with $4 \mathrm{mg} / \mathrm{kg}$ and $8 \mathrm{mg} / \mathrm{kg}$ racemic ketamine combined with a fixed dose of $0.5 \mathrm{mg}$ midazolam seems to be an optimal dose during severely painful paediatric burn wound care procedures. Levels of pain were low in all groups, but children with a dose of $4 \mathrm{mg} / \mathrm{kg}$ had a higher frequency of tachycardia. A dose of $8 \mathrm{mg} / \mathrm{kg}$ resulted in deeper sedation and hypersalivation. Procedure feasibility was affected using the lowest dose and recovery prolonged when using the higher dose. 


\section{ACKNOWLEDGEMENTS}

There are many people I would like to express my gratitude to for the inspiration, support and encouragement that they have given me during the realisation of this thesis.

My deepest gratitude to my supervisors, Lena Nilsson, Andreas Nilsson and Folke Sjöberg. Lena, I am so grateful that you have been my supervisor. Your knowledge and experience along with your commitment and accuracy describe just some of your qualities. You have always been there for advice and guidance but without giving away the challenge facing me. I admire and sometimes wished I have had a fraction of your "effectiveness" (or was it "efficiency")! Andreas, your sense for logic, order and correctness improved my work by letting me dig deeper into science to find the correct answer. Thanks for your patience in answering the same questions over and over again, until I finally got it (hopefully). Apart from the gain in knowledge and experience during these last years, I have also developed olfactory adaptation. Folke, to work with a visionary like you is not always easy! Always several steps ahead of me with new perspectives and ideas on what will come next. For example, "...why do a halfdoctor when you can do a complete degree..." or "...then we have to find a date for a half-time seminar...", spoken after being approved for $\mathrm{PhD}$ studies.

Thanks to Professor Michelle Chew at the Division of Anaesthesiology; Anna Oscarsson Tibblin, director of the Department of Anaesthesia and Intensive Care; Martin Golster and Eva-Lena Zetterlund, former director of the Department of Anaesthesia and Surgical Care; Henrik Appelberg, head of Operation Syd; Karin Bjönström-Karlsson, former head of Operation Syd; Anna Nilsson, nursing chief, for their encouragement, support and decisions during my $\mathrm{PhD}$ studies.

Thanks to all my colleagues at the Department of Anaesthesia and Intensive Care at Linköping University Hospital over the years for the support, understanding and exchange of knowledge and clinical experience. All of you play an important role when taking care of patients and are amazing in what you do, never forget that!

Thanks for support and help from numerous colleagues within the team at the Surgical Clinic. 
I was delighted to be part of the cheerful and hardworking bronchoscopic team at the Department of Pulmonary Medicine. The mixture of personality, knowledge and experience makes it a perfect and successful blend!

Thanks, Lars Bernfort, for introducing me to economic evaluation within healthcare and advice regarding economy (strictly professional, not personal).

With a tireless approach and without sacrificing quality the burn wound care team at the National Burn Centre in Linköping made a significant contribution, and especially the nurse anaesthetists Angelica Höök and Karin Berg.

Thank you Ewa Sandberg and Jonas Andersson for solving all the practicalities concerning my schedule and financial issues during my period of research.

Many thanks to the monitors at Forum Östergötland for the validation of the collected data and the statistician Mats Fredriksson who makes statistics understandable, even for me.

Thanks to my former supervisor Ann-Christin von Vogelsang, who introduced me into the field of research at the Red Cross University in Stockholm. Oskar Karlsson, my friend and co-author in previous academic works with a focus on patient-controlled devices; I missed you this time...

With experience of voluntary work within InvolvAid (formerly I Aid Africa) I have understood that help and improvement can be done in different ways and research is one of them. Napenda kumshukuru rafiki yangu Elimeleki Katani na familia kuelewa mambo muhimu katika maisha. Thanks, my friend Henrik Hjelmgren for supporting and taking care of the organization, Henrik you are up next! Thank you my friend and colleague Carolin Hermansson for times of socialisation during the years, hope to see you within research in the future!

Vielen Dank auch an meine Eltern, die immer an mich geglaubt haben und an meiner Forschung Intresse gezeigt hatten. Thanks to my siblings Ita, Dan and Gad and Mirjam with families, always there to help if necessary and giving me other perspectives on life. My mother-in-law Ingrid for supporting us with all types of practicalities making the "life-puzzle" a little bit easier to handle.

Finally, but most important, my family, Karolina and Miriam... I am so fortunate to have you both in my life! I love you both equally much, even if Miriam says that I should love her more! Karolina, neither words nor pictures can explain the 
gratitude I feel for your support during all years. Sharing my life with you makes me happy and proud. With you by my side and the never-ending love we feel for each other, everything is possible to achieve, even research! Sist och yngst, Miriam, min fina dotter, så lycklig och stolt du gör mig varje dag! Du kan få mig på andra tankar och göra en dålig dag att bli helt underbar. Tiden stannar upp ett slag när vi är tillsammans men rusar snart iväg igen... Min flicka, var stolt för den du är, ta tillvara på livet å följ dina drömmar! 
Procedural sedation - Aspects on methods, safety and effectiveness 


\section{REFERENCES}

1 - McQuaid KR, Laine L. A systematic review and meta-analysis of randomized, controlled trials of moderate sedation for routine endoscopic procedures. Gastrointest Endosc. 2008;67(6):910-23.

2 - American Society for Gastrointestinal Endoscopy (ASGE) Standards of Practice Committee, Early DS, Lightdale JR, Vargo JJ 2nd, Acosta RD, Chandrasekhara $\mathrm{V}$, et al. Guidelines for sedation and anesthesia in GI endoscopy. Gastrointest Endosc. 2018;87(2):327-37.

3 - Du Rand IA, Blaikley J, Booton R, Chaudhuri N, Gupta V, Khalid S, et al. British Thoracic Society guideline for diagnostic flexible bronchoscopy in adults: accredited by NICE. Thorax. 2013;68 Suppl 1:i1-i44.

4 - Wang D, Chen C, Chen J, Xu Y, Wang L, Zhu Z, et al. The use of propofol as a sedative agent in gastrointestinal endoscopy: a meta-analysis. PLoS One. 2013;8(1):e53311.

5 - Wang Z, Hu Z, Dai T. The comparison of propofol and midazolam for bronchoscopy: A meta-analysis of randomized controlled studies. Medicine (Baltimore). 2018;97(36):e12229.

6 - Farmaceutiska Specialiteter i Sverige (FASS). Propofol- ${ }^{\circledR}$ Lipuro [Internet]. Stockholm: Läkemedelsindustriföreningens Service AB (LIF); 2019 [updated 2017-05-12; cited 2019-04-10]. Available from: https://www.fass.se/LIF/product?userType $=0 \&$ nplId $=20000825000258$

7 - Farmaceutiska Specialiteter i Sverige (FASS). Midazolam Accord [Internet]. Stockholm: Läkemedelsindustriföreningens Service AB (LIF); 2019 [updated 2018-08-06; cited 2019-04-10]. Available from:

https://www.fass.se/LIF/product?userType=0\&nplId=20070714000034.

8 - American Society of Anestesiologists (ASA). Continuum of Depth of Sedation: Definition of General Anesthesia and Levels of Sedation/Analgesia [Internet]. Committee on Quality Management and Departmental Administration; 2019 [updated 2014-10-15; cited 2019-04-10]. Available from: https://www.asahq.org/standards-and-guidelines/continuum-of-depth-of-sedationdefinition-of-general-anesthesia-and-levels-of-sedationanalgesia.

9 - Newton T, Pop I, Duvall E. Sedation scales and measures--a literature review. SAAD Dig. 2013;29:88-99.

10 - Chernik DA, Gillings D, Laine H, Hendler J, Silver JM, Davidson AB, et al. Validity and reliability of the Observer's Assessment of Alertness/Sedation Scale: study with intra-venous midazolam. J Clin Psychopharmacol. 1990;10(4):244-51. 
11 - Dumonceau JM, Riphaus A, Beilenhoff U, Vilmann P, Hornslet P, Aparicio JR, et al. European curriculum for sedation training in gastrointestinal endoscopy: position statement of the European Society of Gastrointestinal Endoscopy (ESGE) and European Society of Gastroenterology and Endoscopy Nurses and Associates (ESGENA). Endoscopy. 2013;45(6):496-504.

12 - Svensk Förening för Anestesi och Intensivvård (SFAI). Midazolam Accord [Internet]. Malmö: Svensk Förening för Anestesi och Intensivvård; 2019 [updated 2015-02-12; cited 2019-04-10]. Available from:

https://sfai.se/riktlinje/medicinska-rad-och-riktlinjer/anestesi/procedurrelateradpropofolsedering.

13 - Behrens A, Kreuzmayr A, Manner H, Koop H, Lorenz A, Schaefer C, et al. Acute sedation-associated complications in GI endoscopy (ProSed 2 Study): results from the prospective multicentre electronic registry of sedation-associated complications. Gut. 2018;68(3). Available from doi: 10.1136/gutjnl-2015-311037.

14 - Vargo JJ, DeLegge MH, Feld AD, Gerstenberger PD, Kwo PY, Lightdale JR, et al. Multisociety sedation curriculum for gastrointestinal endoscopy. Gastrointest Endosc. 2012;76:e1-25.

15 - Sharma VK, Nguyen CC, Crowell MD, Lieberman DA, de Garmo P, Fleischer DE, et al. A national study of cardiopulmonary unplanned events after GI endoscopy. Gastrointest Endosc. 2007;66(1):27-34.

16 - American Society of Anesthesiologists Committee. Practice guidelines for preoperative fasting and the use of pharmacologic agents to reduce the risk of pulmonary aspiration: application to healthy patients undergoing elective procedures: an updated report by the American Society of Anesthesiologists Committee on Standards and Practice Parameters. Anesthesiology. 2011;114(3):495-511.

17 - Vargo JJ, Niklewski PJ, Williams JL, Martin JF, Faigel DO. Patient safety during sedation by anesthesia professionals during routine upper endoscopy and colonoscopy: an analysis of 1.38 million procedures. Gastrointest Endosc. 2017;85(1):101-8.

18 - Stahl DL, Richard KM, Papadimos TJ. Complications of bronchoscopy: A concise synopsis. Int J Crit Illn Inj Sci. 2015;5(3):189-95.

19 - Aldrete JA. The post-anesthesia recovery score revisited. J Clin Anesth. 1995;7(1):89-91.

20 - Chung F. Discharge criteria--a new trend. Can J Anaesth. 1995;42(11):1056-8.

21 - Berg K, Idvall E, Nilsson U, Franzén Årestedt K, Unosson M. Psychometric evaluation of the post-discharge surgical recovery scale. J Eval Clin Pract. 2010;16(4):794-801. 
22 - Idvall E, Berg K, Unosson M, Brudin L, Nilsson U. Assessment of recovery after day surgery using a modified version of quality of recovery-40. Acta Anaesthesiol Scand. 2009;53(5):673-7.

23 - Daza JF, Tan CM, Fielding RJ, Brown A, Farrokhyar F, Yang I. Propofol administration by endoscopists versus anesthesiologists in gastrointestinal endoscopy: a systematic review and meta-analysis of patient safety outcomes. Can J Surg. 2018;61(4):226-36.

24 - Rex DK, Deenadayalu VP, Eid E, Imperiale TF, Walker JA, Sandhu K, et al. Endoscopist-directed administration of propofol: a worldwide safety experience. Gastroenterology. 2009;137(4):1229-37.

25 - Rex DK, Heuss LT, Walker JA, Qi R. Trained registered nurses/endoscopy teams can administer propofol safely for endoscopy. Gastroenterology. 2005;129(5):1384-91.

26 - Clark G, Licker M, Younossian AB, Soccal PM, Frey JG, Rochat T, et al. Titrated sedation with propofol or midazolam for flexible bronchoscopy: a randomised trial. Eur Respir J. 2009;34(6):1277-83

27 - Stolz D, Kurer G, Meyer A, Chhajed PN, Pflimlin E, Strobel W, et al. Propofol versus combined sedation in flexible bronchoscopy: a randomised non-inferiority trial. Eur Respir J. 2009;34(5):1024-30.

28 - Kreienbühl L, Elia N, Pfeil-Beun E, Walder B, Tramèr MR. Patient-controlled versus clinician-controlled sedation with propofol: systematic review and metaanalysis with trial sequential analyses. Anesth Analg. 2018;127(4):873-80.

29 - Loper KA, Ready LB, Brody M. Patient-controlled anxiolysis with midazolam. Anesth Analg. 1988;67(11):1118-9.

30 - Maslekar S, Balaji P, Gardiner A, Culbert B, Monson JR, Duthie GS. Randomized controlled trial of patient-controlled sedation for colonoscopy: Entonox vs modified patient-maintained target-controlled propofol. Colorectal Dis. 2011;13(1):48-57.

31 - Johnson LR, Magnani B, Chan V, Ferrante FM. Modifiers of patient-controlled analgesia efficacy. I. Locus of control. Pain. 1989;39(1):17-22.

32 - Rotter JB. Generalized expectancies for internal versus external control of reinforcement. Psychol Monogr. 1966;80(1):1-28.

33 - Osborne GA, Rudkin GE, Jarvis DA, Young IG, Barlow J, Leppard PI. Intraoperative patient-controlled sedation and patient attitude to control. A crossover comparison of patient preference for patient-controlled propofol and propofol by continuous infusion. Anaesthesia. 1994;49(4):287-92.

34 - Lee DW, Chan AC, Wong SK, Li AC, Sze TS, Chung SC. The safety, feasibility, and acceptability of patient-controlled sedation for colonoscopy: prospective study. Hong Kong Med J. 2004;10(2):84-8. 
35 - Heuss LT, Drewe J, Schnieper P, Tapparelli CB, Pflimlin E, Beglinger C. Patientcontrolled versus nurse-administered sedation with propofol during colonoscopy. A prospective randomized trial. Am J Gastroenterol. 2004;99(3):511-8.

36 - Wu Y, Jia N, Zhao C, Li Y, Shi XP, Li YW, et al. Synergistic antinociception of propofol-alfentanil combination in mice. Pharmacol Biochem Behav. 2014;116:25-9.

37 - Sultan SS. Patient-controlled sedation with propofol/remifentanil versus propofol/alfentanil for patients undergoing outpatient colonoscopy, a randomized, controlled double-blind study. Saudi J Anaesth. 2014;8(Suppl 1):S36-40.

38 - Choi J, Choi H, Kang HS, Kang H. Comparison of alfentanil and remifentanil for the use of patient controlled sedation under local anesthesia during ear, nose and throat surgery. Korean J Anesthesiol. 2009;56(5):507-12.

39 - Nilsson A, Nilsson L, Ustaal E, Sjöberg F. Alfentanil and patient-controlled propofol sedation - facilitate gynaecological outpatient surgery with increased risk of respiratory events. Acta Anaesthesiol Scand. 2012;56(9):1123-9.

40 - Mazanikov M, Udd M, Kylänpää L, Mustonen H, Lindström O, Halttunen J, et al. Patient-controlled sedation for ERCP: a randomized double-blind comparison of alfentanil and remifentanil. Endoscopy. 2012;44(5):487-92.

41 - Practice Guidelines for Moderate Procedural Sedation and Analgesia 2018: a report by the American Society of Anesthesiologists Task Force on Moderate Procedural Sedation and Analgesia, the American Association of Oral and Maxillofacial Surgeons, American College of Radiology, American Dental Association, American Society of Dentist Anesthesiologists, and Society of Interventional Radiology. Anesthesiology. 2018;128(3):437-79.

42 - Farmaceutiska Specialiteter i Sverige (FASS). Robinul ${ }^{\circledR}$ [Internet]. Stockholm: Läkemedelsindustriföreningens Service AB (LIF); 2019 [updated 2016-09-28; cited 2019-04-10]. Available from:

https://www.fass.se/LIF/product?userType=0\&nplId=19830118000047.

43 - Stoelting RK, Hillier SC. Handbook of pharmacology and physiology in anesthetic practice. 2nd ed. Philadelphia: Lippincott Williams \& Wilkins; 2006. Chapter 10, Anticholinergic drugs; p. 267-76.

44 - Cowl CT, Prakash UB, Kruger BR. The role of anticholinergics in bronchoscopy. A randomized clinical trial. Chest. 2000;118(1):188-92.

45 - Malik JA, Gupta D, Agarwal AN, Jindal SK. Anticholinergic premedication for flexible bronchoscopy: a randomized, double-blind, placebo-controlled study of atropine and glycopyrrolate. Chest. 2009;136(2):347-54.

46 - Hwang J, Jeon Y, Park HP, Lim YJ, Oh YS. Comparison of alfetanil and ketamine in combination with propofol for patient-controlled sedation during fiberoptic bronchoscopy. Acta Anaesthesiol Scand. 2005;49(9):1334-8. 
47 - Inadomi JM, Gunnarsson CL, Rizzo JA, Fang H. Projected increased growth rate of anesthesia professional-delivered sedation for colonoscopy and EGD in the United States: 2009 to 2015. Gastrointest Endosc. 2010;72(3):580-6.

48 - Inadomi JM. Editorial: Endoscopic sedation: who, which, when? Am J Gastroenterol. 2017;112(2):303-5.

49 - Roseveare C, Seavell C, Patel P, Criswell J, Kimble J, Jones C, et al. Patientcontrolled sedation and analgesia, using propofol and alfentanil, during colonoscopy: a prospective randomized controlled trial. Endoscopy. 1998;30(9):768-73.

50 - Vargo J. Patient-controlled sedation for endoscopic procedures. Gastroenterol Hepatol. 2008;4(5):329-31.

51 - Stevens BJ, Abbott LK, Yamada J, Harrison D, Stinson J, Taddio A, et al. Epidemiology and management of painful procedures in children in Canadian hospitals. CMAJ. 2011;183(7):E403-10.

52 - Anand KJ, Scalzo FM. Can adverse neonatal experiences alter brain development and subsequent behavior? Biol Neonate. 2000;77(2):69-82.

53 - Kennedy RM, Luhmann JD. The "ouchless emergency department". Getting closer: advances in decreasing distress during painful procedures in the emergency department. Pediatr Clin North Am. 1999;46(6):1215-47.

54 - Moffatt C, Franks P, Hollingworth H. Pain at wound dressing changes [Internet]. London: Medical Education Partnership Ltd.; 2004 [cited 2019-04-10]. Available from:

https://ewma.org/fileadmin/user_upload/EWMA.org/Position_documents_20022008/position_doc2002_ENGLISH.pdf

55 - Beltramini A, Milojevic K, Pateron D. Pain assessment in newborns, infants, and children. Pediatr Ann. 2017;46(10):e387-e395.

56 - Merkel SI, Voepel-Lewis T, Shayevitz JR, Malviya S. The FLACC: a behavioral scale for scoring postoperative pain in young children. Pediatr Nurs. 1997;23(3):293-7.

57 - Malviya S, Voepel-Lewis T, Tait AR, Merkel S, Tremper K, Naughton N. Depth of sedation in children undergoing computed tomography: validity and reliability of the University of Michigan Sedation Scale (UMSS). Br J Anaesth. 2002;88(2):241-5.

58 - Wilson RD, Nichols RJ, McCoy NR. Dissociative anesthesia with CI-581 in burned children. Anesth Analg. 1967;46(6):719-24.

59 - Sherwin TS, Green SM, Khan A, Chapman DS, Dannenberg B. Does adjunctive midazolam reduce recovery agitation after ketamine sedation for pediatric procedures? A randomized double blind placebo controlled trial. Ann Emerge Med. 2000;35(3):229-38. 
60 - Beebe DS, Belani KG, Chang PN, Hesse PS, Schuh JS, Liao JC, et al. Effectiveness of preoperative sedation with rectal midazolam, ketamine, or their combination in young children. Anesth Analg. 1992;75(6):880-4.

61 - Wang X, Zhou ZJ, Zhang XF, Zheng S. A comparison of two different doses of rectal ketamine added to $0.5 \mathrm{mg} \times \mathrm{kg}(-1)$ midazolam and $0.02 \mathrm{mg} \mathrm{x} \mathrm{kg}(-1)$ atropine in infants and young children. Anaesth Intensive Care. 2010;38(5):900-4.

62 - Holm-Knudsen R, Sjøgren P, Laub M. Midazolam and ketamine for rectal premedication and induction of anesthesia in children. Anaesthesist. 1990;39(5):255-7.

63 - van der Bijl P, Roelofse JA, Stander IA. Rectal ketamine and midazolam for premedication in pediatric dentistry. J Oral Maxillofac Surg. 1991;49(10):1050-4.

64 - Gales A, Maxwell S. Ketamine: recent evidence and current uses [Internet]. London: World Federation of Societies of Anesthesiologists; 2018 [updated 201806-12; cited 2019-04-10]. Available from:

https://www.wfsahq.org/components/com_virtual_library/media/3a6c6301ec0cc1f af507f2959ae1 ea1a-atow-381-00-01.pdf.

65 - Ozdemir D, Kayserili E, Arslanoglu S, Gulez P, Vergin C. Ketamine and midazolam for invasive procedures in children with malignancy: a comparison of routes of intravenous, oral, and rectal administration. J Trop Pediatr. 2004;50(4):224-8.

66 - Hanna RM, Borchard RE, Schmidt SL. Pharmacokinetics of ketamine $\mathrm{HCl}$ and metabolite I in the cat: A comparison of i.v., i.m., and rectal administration. J Vet Pharmacol Ther. 1988;11(1):84-93.

67 - Sarkar MA. Drug metabolism in the nasal mucosa. Pharm Res. 1992;9(1):1-9.

68 - Jannin V, Lemagnen G, Gueroult P, Larrouture D, Tuleu C. Rectal route in the 21st century to treat children. Adv Drug Deliv Rev. 2014;73:34-49.

69 - Bayat A, Ramaiah R, Bhananker SM. Analgesia and sedation for children undergoing burn wound care. Expert Rev Neurother. 2010;10(11):1747-59.

70 - Kliegman RM, Stanton B, St. Geme J, Schor NF. Nelson textbook of pediatrics. 20th ed. Philadelphia: Elsevier; 2015. Chapter 2, Growth, development, and behavior; p. 279-96.

71 - Stevic M, Ristic N, Budic I, Ladjevic N, Trifunovic B, Rakic I. Comparison of ketamine and ketofol for deep sedation and analgesia in children undergoing laser procedure. Lasers Med Sci. 2017;32(7):1525-33.

72 - Alderete JA. The post-anesthesia recovery score revisited. J Clin Anesth. 1995;7(1):89-91.

73 - Gillham MJ, Hutchinson RC, Carter R, Kenny GN. Patient-maintained sedation for ERCP with a target-controlled infusion of propofol: a pilot study. Gastrointest Endosc. 2001;54(1):14-7. 
74 - Krol M, Brouwer W. Unpaid work in health economic evaluations. Soc Sci Med. 2015;144:127-37.

75 - Wimo A, Jönsson L, Fratiglioni L, Sandman PO, Gustavsson A, Sköldunger A, et al. The societal costs of dementia in Sweden 2012-relevance and methodological challenges in valuing informal care. Alzheimers Res Ther. 2016;8(1):59.

76 - Johannesson M, Borgquist L, Jönsson B, Rastam L. The costs of treating hypertension-an analysis of different cut-off points. Health Policy. 1991;18(2):141-50.

77 - Jokelainen J, Udd M, Kylänpää L, Mustonen H, Halttunen J, Lindström O, et al. How patient-controlled sedation is adopted in clinical practice of sedation for endoscopic retrograde cholangiopancreatography? A prospective study of 1196 cases. Scand J Gastroenterol. 2017;52(2):166-72.

78 - Zhang R, Lu Q, Wu Y. The comparison of midazolam and propofol in gastrointestinal endoscopy: a systematic review and meta-analysis. Surg Laparosc Endosc Percutan Tech. 2018;28(3):153-8.

79 - Wadhwa V, Issa D, Garg S, Lopez R, Sanaka MR, Vargo JJ. Similar risk of cardiopulmonary adverse events between propofol and traditional anesthesia for gastrointestinal endoscopy: a systematic review and meta-analysis. Clin Gastroenterol Hepatol. 2017;15(2):194-206.

80 - Krugliak P, Ziff B, Rusabrov Y, Rosenthal A, Fich A, Gurman GM. Propofol versus midazolam for conscious sedation guided by processed EEG during endoscopic retrograde cholangiopancreatography: a prospective, randomized, double-blind study. Endoscopy. 2000;32(9):677-82.

81 - Farmaceutiska Specialiteter i Sverige (FASS). Flumazenil Fresenius Kabi [Internet]. Stockholm: Läkemedelsindustriföreningens Service AB (LIF); 2019 [updated 2015-06-26; cited 2019-04-10]. Available from: https://www.fass.se/LIF/product?userType=0\&nplId=20050620000588.

82 - Wille RT, Chaffee BW, Ryan ML, Elta GH, Walter V, Barnett JL. Pharmacoeconomic evaluation of flumazenil for routine outpatient EGD. Gastrointest Endosc. 2000;51(3):282-7.

83 - Williamson BH, Nolan PJ, Tribe AE, Thompson PJ. A placebo controlled study of flumazenil in bronchoscopic procedures. Br J Clin Pharmacol. 1997;43(1):77-83.

84 - Gasparović S, Rustemović N, Opacić M, Bates M, Petrovecki M. Comparison of colonoscopies performed under sedation with propofol or with midazolam or without sedation. Acta Med Austriaca. 2003;30(1):13-6.

85 - Clarkson K, Power CK, O'Connell F, Pathmakanthan S, Burke CM. A comparative evaluation of propofol and midazolam as sedative agents in fiberoptic bronchoscopy. Chest. 1993;104(4):1029-31. 
86 - Singh SA, Prakash K, Sharma S, Dhakate G, Bhatia V. Comparison of propofol alone and in combination with ketamine or fentanyl for sedation in endoscopic ultrasonography. Korean J Anesthesiol. 2018;71(1):43-7.

87 - Wehrmann T, Kokabpick S, Lembcke B, Caspary WF, Seifert H. Efficacy and safety of intravenous propofol sedation during routine ERCP: a prospective, controlled study. Gastrointest Endosc. 1999;49(6):677-83.

88 - Mazanikov M, Udd M, Kylänpää L, Mustonen H, Lindström O, Färkkilä M, et al. A randomized comparison of target-controlled propofol infusion and patientcontrolled sedation during ERCP. Endoscopy. 2013;45(11):915-9.

89 - Lu Y, Hao LX, Chen L, Jin Z, Gong B. Systematic review and meta-analysis of patient-controlled sedation versus intravenous sedation for colonoscopy. Int J Clin Exp Med. 2015;8(11):19793-803.

90 - Ulmer BJ, Hansen JJ, Overley CA, Symms MR, Chadalawada V, Liangpunsakul S, et al. Propofol versus midazolam/fentanyl for outpatient colonoscopy: administration by nurses supervised by endoscopists. Clin Gastroenterol Hepatol. 2003;1(6):425-32.

91 - Organisation for Economic Co-operation and Development (OECD). Health spending [Internet]. Paris: Organisation for Economic Co-operation and Development; 2018 [cited 2019-04-10]. Available from: https://data.oecd.org/healthres/health-spending.htm.

92 - Drummond MF, Sculpher MJ, Claxton K, Stoddart GL, Torrance GW. Methods for the economic evaluation of health care programmes. 4th ed. Oxford: Oxford University Press; 2015. Chapter 1, Introduction to economic evaluation; p. 1-18.

93 - Nilsson S, Brunsson I, Askljung B, Påhlman M, Himmelmann K. A rectally administered combination of midazolam and ketamine was easy, effective and feasible for procedural pain in children with cerebral palsy. Acta Paediatr. 2017;106(3):458-62.

94 - Farmaceutiska Specialiteter i Sverige (FASS). Ketalar ${ }^{\circledR}$ [Internet]. Stockholm: Läkemedelsindustriföreningens Service AB (LIF); 2019 [updated 2019-02-01; cited 2019-04-10]. Available from: https://www.fass.se/LIF/product?userType=0\&nplId=19730302000023.

95 - Cheuk DK, Wong WH, Ma E, Lee TL, Ha SY, Lau YL, et al. Use of midazolam and ketamine as sedation for children undergoing minor operative procedures. Support Care Cancer. 2005;13(12):1001-9.

96 - Isono S. Developmental changes of pharyngeal airway patency: implications for pediatric anesthesia. Paediatr Anaesth. 2006;16(2):109-22.

97 - Roelofse JA, Joubert JJ, Roelofse PG. A double-blind randomized comparison of midazolam alone and midazolam combined with ketamine for sedation of pediatric dental patients. J Oral Maxillofac Surg. 1996;54(7):838-44. 
98 - Bhatt M, Johnson DW, Chan J, Taljaard M, Barrowman N, Farion KJ, et al. Risk Factors for Adverse Events in Emergency Department Procedural Sedation for Children. JAMA Pediatr. 2017;171(10):957-64.

99 - Wathen JE, Roback MG, Mackenzie T, Bothner JP. Does midazolam alter the clinical effects of intravenous ketamine sedation in children? A double-blind, randomized, controlled, emergency department trial. Ann Emerg Med. 2000;36(6):579-88.

100 - Lökken P, Bakstad OJ, Fonnelöp E, Skogedal N, Hellsten K, Bjerkelund CE, et al. Conscious sedation by rectal administration of midazolam or midazolam plus ketamine as alternatives to general anesthesia for dental treatment of uncooperative children. Scand J Dent Res. 1994;102(5):274-80.

101 - Cohen VG, Krauss B. Recurrent episodes of intractable laryngospasm during dissociative sedation with intramuscular ketamine. Pediatr Emerg Care. 2006;22(4):247-9.

102 - Asadi P, Ghafouri HB, Yasinzadeh M, Kasnavieh SM, Modirian E. Ketamine and atropine for pediatric sedation: a prospective double-blind randomized controlled trial. Pediatr Emerg Care. 2013;29(2):136-9.

103 - Shi J, Li A, Wei Z, Liu Y, Xing C, Shi H, et al. Ketamine versus ketamine pluses atropine for pediatric sedation: A meta-analysis. Am J Emerg Med. 2018;36(7):1280-6.

104 - Darlong V, Shende D, Singh M, Garg R, Pandey R, Punj J. Low-versus high-dose combination of midazolam-ketamine for oralpremedication in children for ophthalmologic surgeries. Singapore Med J. 2011;52(7):512-610. 



\section{Papers}

The papers associated with this thesis have been removed for copyright reasons. For more details about these see:

http://urn.kb.se/resolve?urn=urn:nbn:se:liu:diva-156720 



\section{FACULTY OF MEDICINE AND HEALTH SCIENCES}

Linköping University Medical Dissertations No. 1669, 2019

Department of Clinical and Experimental Medicine

Linköping University

SE-581 83 Linköping, Sweden

wwW.liu.se

टि

(4)

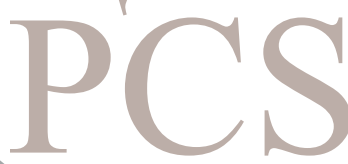

feasibility

s potential

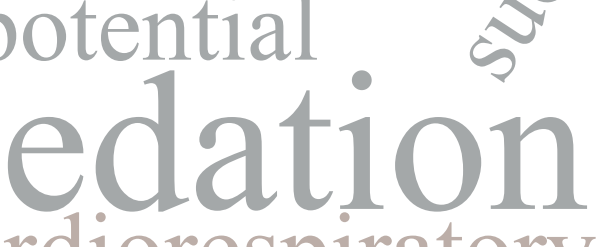

cardiorespiratory

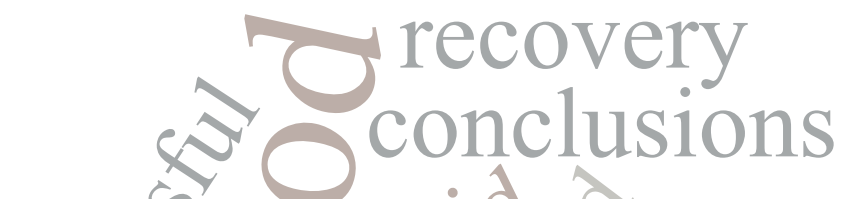

$a_{\text {minj }}$ alternative or rectal

dose $i_{s t_{\mathrm{e}},{ }_{i}}$ conditions

adverse $\log _{\mathrm{g}}$ contribute

complementsaving

execution

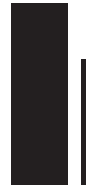

